\title{
Article \\ Nonlinear Dynamics of an Unsymmetric Cross-Ply Square Composite Laminated Plate for Vibration Energy Harvesting
}

\author{
Guoqing Jiang ${ }^{1}$, Ting Dong ${ }^{2, *}$ and Zhenkun Guo ${ }^{1,3}$ \\ 1 College of Aerospace and Civil Engineering, Harbin Engineering University, Harbin 150001, China; \\ jiangguoqing666@hrbeu.edu.cn (G.J.); guozhenkun@bucea.edu.cn (Z.G.) \\ 2 Beijing Key Laboratory of Nonlinear Vibrations and Strength of Mechanical Structures, College of Mechanical \\ Engineering, Beijing University of Technology, Beijing 100124, China \\ 3 Beijing Key Laboratory of Performance Guarantee on Urban Rail Transit Vehicles, Beijing University of Civil \\ Engineering and Architecture, Beijing 102616, China \\ * Correspondence: dongting@emails.bjut.edu.cn or dongtingB2016@163.com
}

Citation: Jiang, G.; Dong, T.; Guo, Z.

Nonlinear Dynamics of an

Unsymmetric Cross-Ply Square Composite Laminated Plate for Vibration Energy Harvesting. Symmetry 2021, 13, 1261. https:// doi.org/10.3390/sym13071261

Academic Editors: Calogero Vetro

Received: 3 June 2021

Accepted: 11 July 2021

Published: 14 July 2021

Publisher's Note: MDPI stays neutral with regard to jurisdictional claims in published maps and institutional affiliations.

Copyright: (๑) 2021 by the authors. Licensee MDPI, Basel, Switzerland. This article is an open access article distributed under the terms and conditions of the Creative Commons Attribution (CC BY) license (https:// creativecommons.org/licenses/by/ $4.0 /)$.

\begin{abstract}
The nonlinear behaviors and energy harvesting of an unsymmetric cross-ply square composite laminated plate with a piezoelectric patch is presented. The unsymmetric cross-ply square composite laminated plate has two stable equilibrium positions by applying thermal stress, thus having snap-through with larger amplitude between the two stable equilibrium positions relative to the general laminated plate. Based on the von-Karman large deformation theory, the nonlinear electromechanical coupling equations of motion of the unsymmetric composite laminated plate with a piezoelectric patch are derived by using Hamilton's principle. The influence of the base excitation amplitude on nonlinear behaviors and energy harvesting are investigated. For different base excitation amplitudes, the motions of the system demonstrate periodic motion, quasi-periodic motion, chaotic motion and snap-through, and two single-well chaotic attractors and a two-well chaos attractor coexist. Moreover, the power generation efficiency is optimal when the excitation amplitude is in a certain range due to its own unique nonlinear characteristics. The unsymmetric cross-ply square composite laminated plate subjected to thermal stress can actually be called a kind of bistable composite shell structure that has a broad application prospect in combination with morphing aircraft, large deployable antenna and solar panel, which are very likely to have nonlinear vibration.
\end{abstract}

Keywords: nonlinear vibration; energy harvesting; chaotic motions; snap-through

\section{Introduction}

Vibration phenomenon and its energy are ubiquitous in nature and life. There are various forms of vibration in various mechanical equipment, vehicles, ocean waves, human activities and so on. How to effectively use vibration has become the focus of attention. Energy harvesting has been widely concerned because of its advantages and great engineering application value. Energy-harvesting devices can extract energy from mechanical vibration [1,2], human and animal movement [3,4], wind or air flow [5,6], ocean current [7] and road and bridge vibration [8]. Ideally, the vibration energy harvesting can replace chemical battery [9] and can also supply power for wireless sensor network equipment [10]. An electromagnetic energy harvester for freight railcars was presented to enable the smart technologies, of which design, modeling, in-lab and onboard field-tests were implemented [2]. A previously introduced piezoelectric rotational harvester was taken, relying on beam plucking for the energy conversion, to the next step by testing the device during a halfmarathon race [3]. The feasibility of employing these vibrational energy harvesters was considered on flying vertebrates for the purpose of powering a bio-logging device [4]. A dynamic model and behavior of a novel double-beam piezo-magneto-elastic nonlinear wind energy harvester (DBPME-WEH) is investigated, which is a double-beam structure 
and contains the magnet-induced bistable nonlinearity to enhance the performance of the galloping-based vibration energy harvesting [5]. An experimental study of wind energy harvesting by self-sustained oscillations (flutter) of a flexible piezoelectric membrane fixed in a novel orientation called the "inverted flag" is described [6]. Buoy-type ocean-wave energy converters were designed to exhibit resonant responses when subject to excitation by ocean waves. A novel excitation scheme was proposed which has the potential to improve the energy-harvesting capabilities of these converters [7]. With a nonlinear X-shaped structure connected with piezoelectric harvesters through two types of special mounting configurations (horizontal and vertical cases), novel coupled vibration energy-harvesting systems were purposely constructed and investigated for exploiting nonlinearity and structural coupling effect in vibration energy harvesting [8]. A wide variety of nanomaterials were being explored for technologies that can extract energy from the environment to generate electrical power for sensors and other devices [9]. A ME/EM composite VEH was proposed that can simultaneously obtain a high voltage, large current, high power and wide bandwidth compared to a traditional single ME VEH or single EM VEH [10].

Energy-harvesting devices use a transducer to convert mechanical vibrations to electrical energy. The main methods of transduction include electromagnetic [11], electrostatic [12-14], triboelectric [15] and piezoelectric [16,17]. The model of energy harvesting in the environment by electromagnetic conversion has been established maturely, and it has been implemented in many vibration energy harvesters [18]. Amirtharajah and chandrakasan [19] proposed an electromagnetic vibration energy-harvesting system, which is mainly composed of permanent magnet, coil, shell, spring and lumped mass. Mann and Owens [20] proposed an electromagnetic induction energy harvester to transform the vibration energy and use it for electric loads. The energy harvester consists of a movable suspended magnet and several static external magnets. However, the electromagnetic power generation device is vulnerable to the electromagnetic interference of the surrounding environment, and it is not convenient for the miniaturization design. The electrostatic conversion device is composed of electret and variable capacitors, which change the capacity of the variable capacitance diode under vibration excitation so as to realize energy conversion. Its disadvantage is that it needs additional power supply to provide the initial voltage drive [21]. The theoretical support of piezoelectric conversion is the positive piezoelectric effect of piezoelectric materials. Piezoelectric energy harvesting has the advantages of a simple structure, easy system integration, high power density, low cost and miniaturization and has attracted the attention of domestic and foreign scholars. Erturk and Inman [22] gave the analytical expressions of the voltage output and excitation frequency of the piezoelectric cantilever beam energy-harvesting system based on the Euler-Bernoulli beam and verified the reliability of the theoretical analysis through experiments. Anton and Sodano [23] designed energy scavenging devices to capture the ambient energy surrounding the electronics and convert it into usable electrical energy. Ferrari et al. [24] designed a multifrequency vibration energy harvester by using three cantilever beams that have the same size and different mass. The system has three resonance frequency points, but when the external excitation frequency deviates from three resonance frequencies, the output power of the system will also be greatly reduced.

A key design index for energy-harvesting devices is the effective operating frequencies bandwidth at which the energy can be extracted. A linear vibration collector $[25,26]$ is only suitable to work near the natural frequencies; when the vibration energy spectrum of environment is wide, the energy efficiency of linear vibration collector will be very low. In order to enhance the harvesting performance and to broaden the harvesting bandwidth, the research objectives of the vibration energy harvester develop to a wide-frequency band, nonlinear, multi-steady state (two or several steady states), multi-degree of freedom and so on $[27,28]$. When the vibration frequency of the external environment does not match the natural frequency of the designed energy harvester, the energy conversion rate will be very low. Therefore, a frequency modulation energy-harvesting system is proposed through adjusting the natural frequency of the harvester to make it the same as the external 
excitation frequency $[29,30]$. However, in most of the cases, the external vibration frequencies in the actual environment are broadband or change with time. In order to improve the energy-harvesting efficiency, it is found that introducing nonlinearity technology into energy harvesting can effectively improve the frequency bandwidth and response. Daqaq et al. [31] studied the nonlinear monostable energy harvester with soft spring characteristics through an analytical analysis and experimental research, obtained the expressions of the output voltage and power under a monostable state by using the multi-scale method and analyzed the influence of the impedance and coupling coefficient on the energy harvester. Yildirim et al. [32] manufactured and researched a parametrically excited cantilever beam in contact with mechanical stoppers. Yuan et al. [33] investigated the nonlinear behaviors of a vibration-based energy harvester. The harvester consists of a circular composite plate with the clamped boundary, a mass and two steel rings. Jin et al. [34] designed an energyharvesting device to realize the double target of reducing the vibration amplitude and harvesting extremely low ambient vibrations. The device consists of a nonlinear energy sink (NES) and a nonlinear energy harvester with cascaded essential nonlinearities. A more complex nonlinear multi-stable design is an important measure to solve the energy harvesting of low-frequency, ultra-low-frequency and low-intensity vibrations to improve the output power and to expand the harvesting frequency bandwidth. At present, according to the formation mechanisms, the bistable energy-harvesting devices can be divided into three types: a bistable piezoelectric energy-harvesting structure of magnetic repulsion [35,36], a bistable piezoelectric energy-harvesting structure of magnetic suction [37] and a bistable piezoelectric energy-harvesting structure of compression buckling [38]. Since then, the emergence of more complex multi-stable energy capture structures further improves the efficiency of energy harvesting [39,40]. Shukla and Pradyumna [41] explored the use of curvilinear fiber in a bimorph energy harvester and investigated the effect on tailoring the resonance frequency and extracted power. Piezoelectric energy harvesting and piezoelectric driving are similar, except for their ultimate purpose. Gohari et al. [42] utilized inclined piezoelectric actuators to drive the twisting deformation of smart laminated cantilever composite plates/beams; proposed a novel explicit analytical solution for obtaining twisting deformation and optimal shape control and developed a series of simple, accurate and robust finite element (FE) analysis models and realistic electromechanical-coupled FE procedures for verification. Gohari et al. [43] developed an analytical solution for the electromechanical flexural response of smart laminated piezoelectric composite rectangular plates encompassing flexible-spring boundary conditions at two opposite edges that can potentially be applied to real-life structural systems, such as smart floors and bridges, and can be used to analyze the flexural deformation response.

Different from traditional energy-harvesting devices that contain only one stable equilibrium position, this study focuses on nonlinear and bistable characteristics. The novelty of this work lies in that the unsymmetric cross-ply square composite laminated plate has two stable equilibrium positions by applying thermal stress, thus having snapthrough with a larger amplitude between the two stable equilibrium positions relative to the general laminated plate.

In this paper, in order to improve the power generation efficiency, a very efficient nonlinear energy harvesting model is designed. An unsymmetric cross-ply square composite laminated plate and a piezoelectric patch are the main components of the energy-harvesting device. Under the experimental conditions, the center of the plate is connected with the exciter through a supporting bar; therefore, it is assumed that the center of the plate is fixed and four edges are kept free, and a base excitation is given at the center. The residual thermal stress is taken into account to make the unsymmetric composite laminated plate have two stable equilibrium positions. A nonlinear dynamic model of an unsymmetric cross-ply square composite laminated plate with a piezoelectric patch is established. The nonlinear dynamics of the unsymmetric cross-ply square composite laminated plate tend to behave as snap-through and chaotic motions as two single-well chaotic attractors, and as two-well chaos attractors coexist, two-well chaotic motion with large amplitude occurs. 
By adjusting the excitation amplitude and frequency, this kind of two-well chaotic motion with a large amplitude will occur in a very wide range of parameters. The nonlinear characteristics of the unsymmetric cross-ply square composite laminated plate can cause snap-through and chaotic motions, which greatly enhance the power generation capacity and greatly improve the power generation efficiency of the energy harvester. When the excitation amplitude is in a specific scope, the motions of the plate around the double-well attractor, the energy harvesting can obtain the highest power generation efficiency and the strongest power generation capacity. Therefore, the research of energy-harvesting devices has great theoretical significance and practical value.

The novelty of this work is that the unsymmetric composite laminated plate has two stable equilibrium positions by applying thermal stress, thus having snap-through with a larger amplitude between the two stable equilibrium positions relative to the general laminated plate.

The unsymmetric cross-ply square composite laminated plate subjected to thermal stress can actually be called a kind of bistable composite shell structure that has a broad application prospect in combination with morphing aircraft, large deployable antenna and a solar panel, which are very likely to have nonlinear vibrations.

\section{Equation of Motion}

The unsymmetric cross-ply square composite laminated plate with a piezoelectric patch is depicted in Figure 1. The structure consists of an unsymmetric cross-ply square composite laminated plate and a piezoelectric patch; the piezoelectric patch is pasted on the top surface of the plate, and the ply angle of the unsymmetric cross-ply square composite laminated plate is $\left[0^{\circ} / 0^{\circ} / 0^{\circ} / 0^{\circ} / 90^{\circ} / 90^{\circ} / 90^{\circ} / 90^{\circ}\right]$, as can be seen in Figure 1 . A cartesian coordinate oxyz is located in the center of the unsymmetric cross-ply square composite laminated plate. The edge lengths of the unsymmetric cross-ply square composite laminated plate in the $x$ and $y$ directions are $2 L_{x}$ and $2 L_{y}$, respectively, and the thickness of the unsymmetric cross-ply square composite laminated plate is $2 H$. The edge lengths of the piezoelectric patch in the $x$ and $y$ directions are $L_{1}$ and $L_{2}$, respectively, and the thickness of the piezoelectric patch is $h^{E}$. Three variables $u, v$ and $w$ are used to denote the displacements of the plate in the $x, y$ and $z$ directions. Under the experimental conditions, the center of the plate is connected with the exciter through a supporting bar. Therefore, it is assumed that the center of the plate is fixed and the four edges are kept free, and a base excitation is given at the center. The unsymmetric cross-ply square composite laminated plate is subjected to a base excitation $Y$. Figure 2 shows the two stable equilibrium positions of the structure subjected to thermal stress.

\subsection{Analysis of Unsymmetric Composite Laminated Plate}

The displacement field according to the classical deformation plate theory for an arbitrary point is assumed to be

$$
\begin{gathered}
u(x, y, z, t)=u_{0}(x, y, t)-z \frac{\partial w_{0}(x, y, t)}{\partial x}, \\
v(x, y, z, t)=v_{0}(x, y, t)-z \frac{\partial w_{0}(x, y, t)}{\partial y}, \\
w(x, y, t)=w_{0}(x, y, t)+Y
\end{gathered}
$$

where $u_{0}, v_{0}$ and $w_{0}$ denote the longitudinal and transverse displacements of the mid-plane, and $z$ is the transverse coordinate of the plate. 


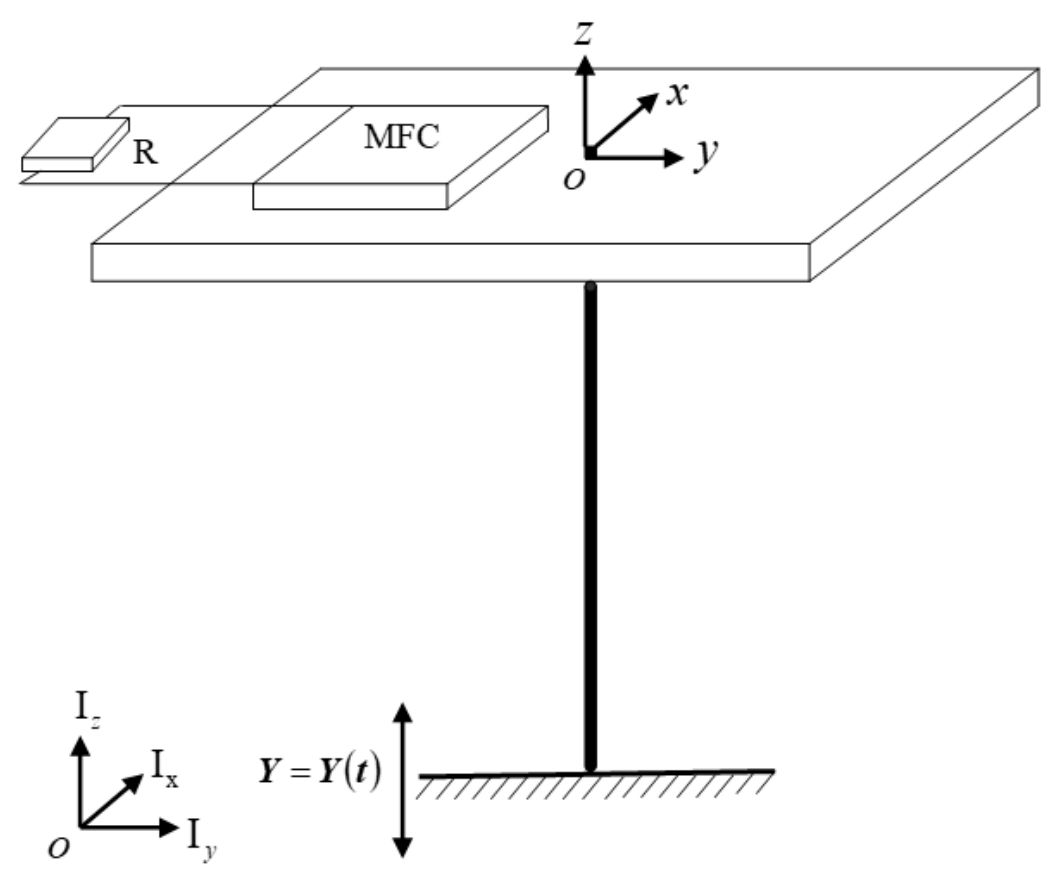

Figure 1. The dynamic model of the unsymmetric composite laminated plate with a piezoelectric patch.

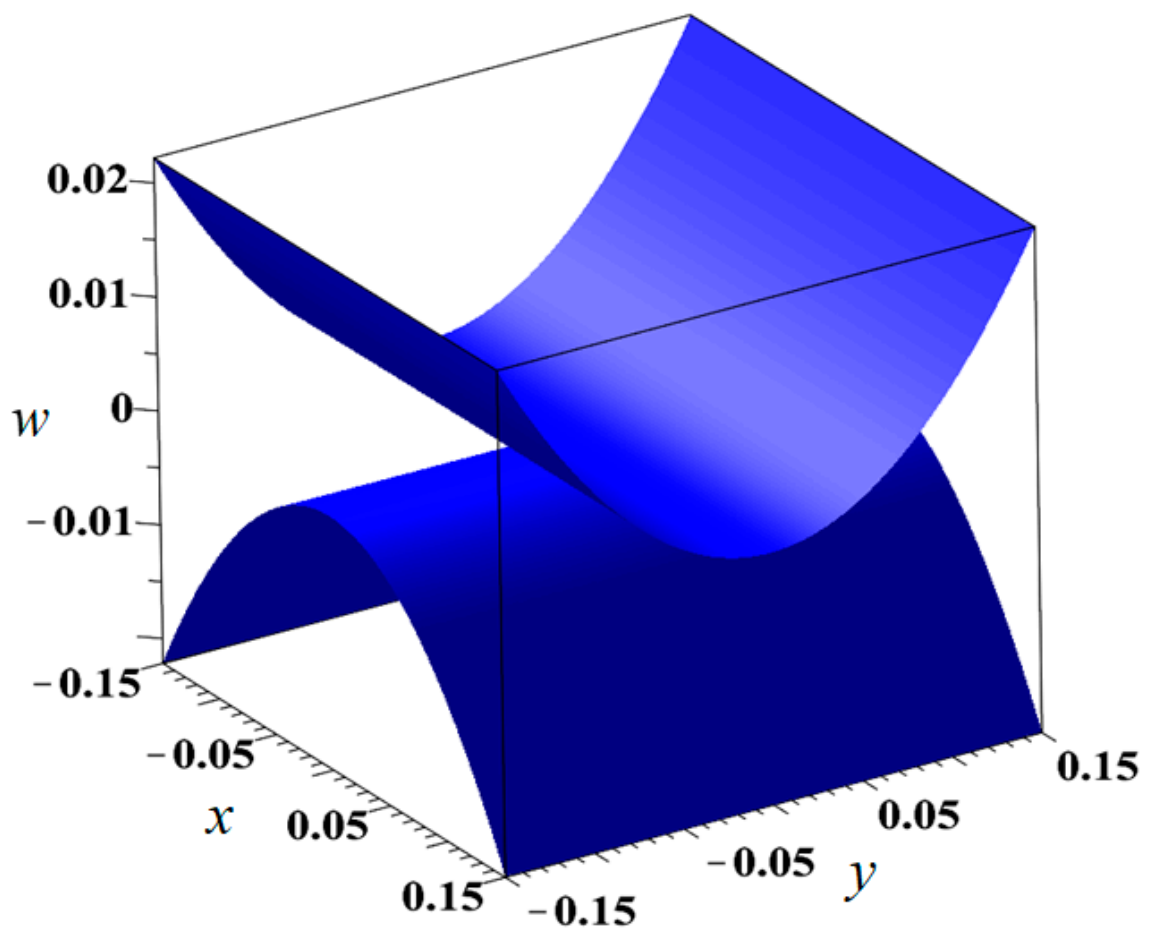

Figure 2. The two stable equilibrium positions of the unsymmetric cross-ply square composite laminated plate subjected to thermal stress. 
Based on the von-Karman large deformation theory, the strain-displacement relations can be obtained:

$$
\begin{gathered}
\left\{\begin{array}{c}
\varepsilon_{x} \\
\varepsilon_{y} \\
\gamma_{x y}
\end{array}\right\}=\left\{\begin{array}{c}
\varepsilon_{x}^{(0)} \\
\varepsilon_{y}^{(0)} \\
\gamma_{x y}^{(0)}
\end{array}\right\}+z\left\{\begin{array}{c}
k_{x} \\
k_{y} \\
k_{x y}
\end{array}\right\}, \\
\left\{\varepsilon_{0}\right\}=\left\{\begin{array}{c}
\varepsilon_{x}^{(0)} \\
\varepsilon_{y}^{(0)} \\
\gamma_{x y}^{(0)}
\end{array}\right\}=\left\{\begin{array}{c}
\frac{\partial u_{0}}{\partial x}+\frac{1}{2}\left(\frac{\partial w_{0}}{\partial x}\right)^{2} \\
\frac{\partial v_{0}}{\partial y}+\frac{1}{2}\left(\frac{\partial w_{0}}{\partial y}\right)^{2} \\
\frac{\partial v_{0}}{\partial x}+\frac{\partial u_{0}}{\partial y}+\frac{\partial w_{0}}{\partial x} \frac{\partial w_{0}}{\partial y}
\end{array}\right\},\{k\}=\left\{\begin{array}{c}
k_{x} \\
k_{y} \\
k_{x y}
\end{array}\right\}=\left\{\begin{array}{c}
-\frac{\partial^{2} w_{0}}{\partial x^{2}} \\
-\frac{\partial^{2} w_{0}}{\partial y^{2}} \\
-2 \frac{\partial^{2} w_{0}}{\partial x \partial y}
\end{array}\right\}
\end{gathered}
$$

where $\left\{\varepsilon_{0}\right\}$ represent the membrane strains, and $\{k\}$ denotes the bending curvature.

The stress-strain relationship of the $k$ th layer is given as follows:

$$
\begin{gathered}
\left\{\begin{array}{c}
\sigma_{x} \\
\sigma_{y} \\
\sigma_{x y}
\end{array}\right\}=\left[\begin{array}{lll}
Q_{11} & Q_{12} & Q_{16} \\
Q_{12} & Q_{22} & Q_{26} \\
Q_{16} & Q_{26} & Q_{66}
\end{array}\right]\left\{\left\{\begin{array}{c}
\varepsilon_{x} \\
\varepsilon_{y} \\
\varepsilon_{x y}
\end{array}\right\}-\left\{\begin{array}{c}
\alpha_{x x} \\
\alpha_{y y} \\
\alpha_{x y}
\end{array}\right\} \Delta T\right\},(k=1,2,3,4) \\
\left\{\begin{array}{c}
\sigma_{x} \\
\sigma_{y} \\
\sigma_{x y}
\end{array}\right\}=\left[\begin{array}{ccc}
Q_{22} & Q_{12} & -Q_{26} \\
Q_{12} & Q_{22} & -Q_{16} \\
-Q_{26} & -Q_{16} & Q_{66}
\end{array}\right]\left\{\left\{\begin{array}{c}
\varepsilon_{x} \\
\varepsilon_{y} \\
\varepsilon_{x y}
\end{array}\right\}-\left\{\begin{array}{c}
\alpha_{y y} \\
\alpha_{x x} \\
\alpha_{x y}
\end{array}\right\} \Delta T\right\},(k=5,6,7,8)
\end{gathered}
$$

where $\alpha_{x x}, \alpha_{y y}$ and $\alpha_{x y}$ are the coefficients of the linear expansion. $\Delta T$ is the temperature change. $Q_{i j}$ is the material elastic constant, and the expression is shown as follows:

$$
Q_{11}=\frac{E_{11}}{1-v_{12} v_{21}}, Q_{22}=\frac{E_{22}}{1-v_{12} v_{21}}, Q_{12}=\frac{E_{22} v_{12}}{1-v_{12} v_{21}}, Q_{16}=Q_{26}=0, Q_{66}=G_{12} .
$$

in which $E_{11}$ and $E_{22}$ are the modulus of elasticity, $v_{12}$ and $v_{21}$ are the Poisson's ratios, $G_{12}$ is the shear modulus and all these coefficients belong to the unsymmetric cross-ply square composite laminated plate.

The stress resultants of the unsymmetric cross-ply square composite laminated plate are represented as follows:

$$
\begin{gathered}
\left\{\begin{array}{l}
N_{x x} \\
N_{y y} \\
N_{x y}
\end{array}\right\}=\left[\begin{array}{lll}
A_{11} & A_{12} & A_{16} \\
A_{12} & A_{22} & A_{26} \\
A_{16} & A_{26} & A_{66}
\end{array}\right]\left[\begin{array}{c}
\varepsilon_{x}^{(0)} \\
\varepsilon_{y}^{(0)} \\
\gamma_{x y}^{(0)}
\end{array}\right]+\left[\begin{array}{lll}
B_{11} & B_{12} & B_{16} \\
B_{12} & B_{22} & B_{26} \\
B_{16} & B_{26} & B_{66}
\end{array}\right]\left[\begin{array}{c}
k_{x} \\
k_{y} \\
k_{x y}
\end{array}\right]-\left\{\begin{array}{l}
N_{x x}^{T} \\
N_{y y}^{T} \\
N_{x y}^{T}
\end{array}\right\}, \\
\left\{\begin{array}{l}
M_{x x} \\
M_{y y} \\
M_{x y}
\end{array}\right\}=\left[\begin{array}{lll}
B_{11} & B_{12} & B_{16} \\
B_{12} & B_{22} & B_{26} \\
B_{16} & B_{26} & B_{66}
\end{array}\right]\left[\begin{array}{c}
\varepsilon_{x}^{(0)} \\
\varepsilon_{y}^{(0)} \\
\gamma_{x y}^{(0)}
\end{array}\right]+\left[\begin{array}{lll}
D_{11} & D_{12} & D_{16} \\
D_{12} & D_{22} & D_{26} \\
D_{16} & D_{26} & D_{66}
\end{array}\right]\left[\begin{array}{c}
k_{x} \\
k_{y} \\
k_{x y}
\end{array}\right]-\left\{\begin{array}{l}
M_{x x}^{T} \\
M_{y y}^{T} \\
M_{x y}^{T}
\end{array}\right\}
\end{gathered}
$$

where $A_{i j}$ are the extensional stiffnesses, $D_{i j}$ are the bending stiffnesses and $B_{i j}$ are the bendingextensional coupling stiffnesses, which are defined in terms of the lamina stiffnesses $Q_{i j}$ as

$$
\begin{gathered}
\left(A_{i j}, B_{i j}, D_{i j}\right)=\int_{0}^{H} Q_{i j}\left(1, z, z^{2}\right) d z+\int_{-H}^{0} Q_{i j}\left(1, z, z^{2}\right) d z \\
=\sum_{k=1}^{4} \int_{z_{k}}^{z_{k+1}} Q_{i j}\left(1, z, z^{2}\right) d z+\sum_{k=5}^{8} \int_{z_{k}}^{z_{k+1}} Q_{i j}\left(1, z, z^{2}\right) d z,(i, j=1,2,6)
\end{gathered}
$$

The thermal force and moment resultants are given as

$$
\begin{aligned}
& \left\{\begin{array}{c}
N_{x x}^{T} \\
N_{y y}^{T} \\
N_{x y}^{T}
\end{array}\right\}=\int_{0}^{H}\left[\begin{array}{lll}
Q_{11} & Q_{12} & Q_{16} \\
Q_{12} & Q_{22} & Q_{26} \\
Q_{16} & Q_{26} & Q_{66}
\end{array}\right]\left[\begin{array}{c}
\alpha_{x x} \\
\alpha_{y y} \\
2 \alpha_{x y}
\end{array}\right] \Delta T d z+\int_{-H}^{0}\left[\begin{array}{ccc}
Q_{22} & Q_{12} & -Q_{26} \\
Q_{12} & Q_{11} & -Q_{16} \\
Q_{26} & Q_{26} & Q_{66}
\end{array}\right]\left[\begin{array}{c}
\alpha_{y y} \\
\alpha_{x x} \\
2 \alpha_{x y}
\end{array}\right] \Delta T d z \\
& \left\{\begin{array}{l}
M_{x x}^{T} \\
M_{y y}^{T} \\
M_{x y}^{T}
\end{array}\right\}=\int_{0}^{H}\left[\begin{array}{lll}
Q_{11} & Q_{12} & Q_{16} \\
Q_{12} & Q_{22} & Q_{26} \\
Q_{16} & Q_{26} & Q_{66}
\end{array}\right]\left[\begin{array}{c}
\alpha_{x x} \\
\alpha_{y y} \\
2 \alpha_{x y}
\end{array}\right] \Delta T z d z+\int_{-H}^{0}\left[\begin{array}{ccc}
Q_{22} & Q_{12} & -Q_{26} \\
Q_{12} & Q_{11} & -Q_{16} \\
Q_{26} & Q_{26} & Q_{66}
\end{array}\right]\left[\begin{array}{c}
\alpha_{y y} \\
\alpha_{x x} \\
2 \alpha_{x y}
\end{array}\right] \Delta T z d z
\end{aligned}
$$




\subsection{Analysis of Piezoelectric Patch}

The stress-strain relationship of the piezoelectric patch is given as follows:

$$
\left\{\begin{array}{c}
\sigma_{x x}^{E} \\
\sigma_{y y}^{E} \\
\sigma_{x y}^{E} \\
D_{z}
\end{array}\right\}=\left\{\begin{array}{cccc}
c_{11}^{E} & c_{12}^{E} & 0 & -e_{31} \\
c_{12}^{E} & c_{22}^{E} & 0 & -e_{32} \\
0 & 0 & c_{66}^{E} & 0 \\
e_{31} & e_{32} & 0 & \epsilon_{33}
\end{array}\right\}
$$

where $e_{i j}$ are the piezoelectric stress constants. $\in_{i i}$ is the dielectric constant. $c_{i j}^{E}$ are the material elastic constants, and the expression is shown as follows:

$$
c_{11}^{E}=\frac{E_{11}^{E}}{1-v_{12}^{E} v_{21}^{E}}, c_{22}^{E}=\frac{E_{22}^{E}}{1-v_{12}^{E} v_{21}^{E}}, c_{12}^{E}=\frac{E_{22}^{E} v_{12}^{E}}{1-v_{12}^{E} v_{21}^{E}}, c_{66}^{E}=G_{12}^{E}
$$

in which $E_{11}^{E}$ and $E_{22}^{E}$ are the modulus of elasticity, $v_{12}^{E}$ and $v_{21}^{E}$ are the Poisson's ratios, $G_{12}^{E}$ is the shear modulus and all these coefficients belong to the piezoelectric patch.

The stress resultants of the piezoelectric patch are represented as follows:

$$
\begin{aligned}
& \left\{\begin{array}{l}
N_{x x}^{E} \\
N_{y y}^{E} \\
N_{x y}^{E}
\end{array}\right\}=\left[\begin{array}{lll}
A_{11}^{E} & A_{12}^{E} & A_{16}^{E} \\
A_{12}^{E} & A_{22}^{E} & A_{26}^{E} \\
A_{16}^{E} & A_{26}^{E} & A_{66}^{E}
\end{array}\right]\left\{\begin{array}{c}
\varepsilon_{x x}^{(0)} \\
\varepsilon_{y y}^{(0)} \\
\gamma_{x y}^{(0)}
\end{array}\right\}+\left[\begin{array}{ccc}
B_{11}^{E} & B_{12}^{E} & B_{16}^{E} \\
B_{12}^{E} & B_{22}^{E} & B_{26}^{E} \\
B_{16}^{E} & B_{26}^{E} & B_{66}^{E}
\end{array}\right]\left\{\begin{array}{c}
\varepsilon_{x x}^{(1)} \\
\varepsilon_{y y}^{(1)} \\
\gamma_{x y}^{(1)}
\end{array}\right\}-\left\{\begin{array}{c}
N_{x x}^{P} \\
N_{y y}^{P} \\
N_{x y}^{P}
\end{array}\right\}, \\
& \left\{\begin{array}{l}
M_{x x}^{E} \\
M_{y y}^{E} \\
M_{x y}^{E}
\end{array}\right\}=\left[\begin{array}{lll}
B_{11}^{E} & B_{12}^{E} & B_{16}^{E} \\
B_{12}^{E} & B_{22}^{E} & B_{26}^{E} \\
B_{16}^{E} & B_{26}^{E} & B_{66}^{E}
\end{array}\right]\left\{\begin{array}{c}
\varepsilon_{x x}^{(0)} \\
\varepsilon_{y y}^{(0)} \\
\gamma_{x y}^{(0)}
\end{array}\right\}+\left[\begin{array}{lll}
D_{11}^{E} & D_{12}^{E} & D_{16}^{E} \\
D_{12}^{E} & D_{22}^{E} & D_{26}^{E} \\
D_{16}^{E} & D_{26}^{E} & D_{66}^{E}
\end{array}\right]\left\{\begin{array}{c}
\varepsilon_{x x}^{(1)} \\
\varepsilon_{y y}^{(1)} \\
\gamma_{x y}^{(1)}
\end{array}\right\}-\left\{\begin{array}{l}
M_{x x}^{P} \\
M_{y y}^{P} \\
M_{x y}^{P}
\end{array}\right\}
\end{aligned}
$$

where $A_{i j}^{E}$ are called extensional stiffnesses, $D_{i j}^{E}$ are called the bending stiffnesses and $B_{i j}^{E}$ are called the bending-extensional coupling stiffnesses, which are defined in terms of the lamina stiffnesses $c_{i j}^{E}$ as

$$
\left(A_{i j}^{E}, B_{i j}^{E}, D_{i j}^{E}\right)=\int_{H}^{H+h^{E}} c_{i j}^{E}\left(1, z, z^{2}\right) d z,(i, j=1,2,6)
$$

\subsection{Equation of Motion of the Unsymmetric Composite Laminated Plate with the} Piezoelectric Patch

The Hamilton's principle will be used in the following analysis to derive the nonlinear governing equations of motions of the unsymmetric cross-ply square composite laminated plate with the piezoelectric patch. The mathematical statement of the Hamilton's principle is given as

$$
\int_{t_{1}}^{t_{2}} \delta\left(T_{\text {total }}-U_{\text {total }}\right) d t+\int_{t_{1}}^{t_{2}} \delta W_{\text {total }} d t=0,
$$

where $T_{\text {total }}, U_{\text {total }}$ and $\delta W_{\text {total }}$ are the kinetic energy, the strain energy and the virtual work done of the unsymmetric composite laminated plate with a piezoelectric patch.

According to Equations (6)-(10), the potential energy of the unsymmetric cross-ply square composite laminated plate is

$$
\begin{gathered}
U_{\mathrm{Lam}}=\frac{1}{2} \sum_{j=1}^{n_{\mathrm{lam}}} \int_{V_{\text {lam }}^{(j)}}\left(\sigma_{x x} \varepsilon_{x x}+\sigma_{y y} \varepsilon_{y y}+\sigma_{x y} \gamma_{x y}\right) d V_{\mathrm{lam}}^{(j)} \\
=\frac{1}{2} \iint_{S_{\mathrm{lam}}}\left(N_{x x} \varepsilon_{x x}^{(0)}+N_{y y} \varepsilon_{y y}^{(0)}+N_{x y} \gamma_{x y}^{(0)}+M_{x x} \varepsilon_{x x}^{(1)}+M_{y y} \varepsilon_{y y}^{(1)}+M_{x y} \gamma_{x y}^{(1)}\right) d x d y,
\end{gathered}
$$


where $S_{\text {lam }}$ and $V_{\text {lam }}$ are the area and volume of the unsymmetric cross-ply square composite laminated plate, respectively. $n_{\mathrm{lam}}$ is the layer number of the plate.

According to Equations (14)-(16), the strain energy of the piezoelectric patch is

$$
\begin{gathered}
\left(U_{\mathrm{pie}}\right)_{\mathrm{m}}=\frac{1}{2} \sum_{i=1}^{n_{\text {pie }}} \int_{V_{\mathrm{pie}}^{(i)}}\left(\sigma_{x x}^{E} \varepsilon_{x x}^{E}+\sigma_{y y}^{E} \varepsilon_{y y}^{E}+\sigma_{x y}^{E} \gamma_{x y}^{E}\right) d V_{\text {pie }}^{(i)} \\
=\frac{1}{2} \iint_{S_{\mathrm{Pie}}}\left(N_{x x}^{E} \varepsilon_{x x}^{(0)}+N_{y y}^{E} \varepsilon_{y y}^{(0)}+N_{x y}^{E} \gamma_{x y}^{(0)}+M_{x x}^{E} \varepsilon_{x x}^{(1)}+M_{y y}^{E} \varepsilon_{y y}^{(1)}+M_{x y}^{E} \gamma_{x y}^{(1)}\right) d x d y,
\end{gathered}
$$

where $S_{\text {pie }}$ and $V_{\text {pie }}$ are the area and volume of the piezoelectric patch, respectively. $n_{\text {pie }}$ is the number of piezoelectric patches.

The electric potential energy of the piezoelectric patch is

$$
\left(U_{\mathrm{pie}}\right)_{\mathrm{el}}=\frac{1}{2} \sum_{i=1}^{n_{\mathrm{pie}}} \int_{V_{\mathrm{pie}}^{(i)}}\left(E_{z} e_{31} \varepsilon_{x x}^{E}+E_{z} e_{32} \varepsilon_{y y}^{E}\right) d V_{\text {pie }}^{(i)}
$$

The potential energy of the piezoelectric patch is

$$
U_{\text {pie }}=\left(U_{\text {pie }}\right)_{\mathrm{m}}-\left(U_{\text {pie }}\right)_{\mathrm{el}} .
$$

The total potential energy of the unsymmetric cross-ply square composite laminated plate with the piezoelectric patch is

$$
U_{\text {total }}=U_{\text {Lam }}+U_{\text {pie }}
$$

The total kinetic energy of the unsymmetric cross-ply square composite laminated plate with the piezoelectric patch is

$$
T_{\text {total }}=\frac{1}{2} \rho_{\text {lam }} \sum_{j=1}^{n_{\text {lam }}} \int_{V_{\text {lam }}^{(j)}}\left(\dot{u}^{2}+\dot{v}^{2}+\dot{w}^{2}\right) d V_{\text {lam }}^{(j)}+\frac{1}{2} \rho_{\text {pie }} \sum_{i=1}^{n_{\text {pie }}} \int_{V_{\text {pie }}^{(i)}}\left(\dot{u}^{2}+\dot{v}^{2}+\dot{w}^{2}\right) d V_{\text {pie }}^{(i)}
$$

where $\rho_{\text {lam }}$ and $\rho_{\text {pie }}$ are the density of the unsymmetric cross-ply square composite laminated plate and the piezoelectric patch, respectively.

The internal electrical work is given:

$$
W_{i e}=\frac{1}{2} \sum_{i=1}^{n_{\text {pie }}} \int_{V_{\text {pie }}^{(i)}}\left(E_{z} D_{z}\right) d V_{\text {pie }^{\prime}}^{(i)}
$$

where $E_{z}$ is the electric field applied in the $z$ direction, and $D_{z}$ is the electric displacement in the $z$ direction.

The work of the external force is

$$
W=\int_{V_{\text {total }}}(-c \dot{w} w) d V_{\text {total }}-V(t) Q(t),
$$

where $c$ is the damping coefficient. $Q(t)$ is the electric charge quantity and the expression is as follows:

$$
Q(t)=\sum_{i=1}^{n_{\text {pie }}} \int_{V_{\text {pie }}^{(i)}} D_{z} d V_{\text {pie }}^{(i)}
$$


The relationship between the current and voltage is as follows:

$$
V(t)=I(t) R=R \dot{Q}(t),
$$

where $R$ is the external electrical resistance.

The total potential energy of the unsymmetric cross-ply square composite laminated plate with the piezoelectric patch is

$$
W_{\text {total }}=W_{i e}+W .
$$

According to Reference [44], when the unsymmetric cross-ply square composite laminated plate plus the piezoelectric patch is clamped in the center, the static displacements are described by the assumptions:

(1) $u_{s}$ is odd in the $x$ and even in the $y$ directions.

(2) $v_{s}$ is even in the $x$ and odd in the $y$ directions.

(3) $w_{s}$ is even in the $x$ and $y$ directions, and it vanishes at the origin.

Therefore, according to Reference [44], the static displacements can be expressed by

$$
\begin{aligned}
& u_{s}(x, y)=\sum_{m=0}^{N} \sum_{n=0}^{m} u_{n, m-n} x^{n} y^{n-m}, \\
& v_{s}(x, y)=\sum_{m=0}^{N} \sum_{n=0}^{m} v_{n, m-n} x^{n} y^{n-m}, \\
& w_{s}(x, y)=\sum_{m=0}^{N} \sum_{n=0}^{m} w_{n, m-n} x^{n} y^{n-m}
\end{aligned}
$$

It is noticed that Equations (31)-(33) only describes the static displacements; in order to describe the dynamic displacements, we introduced the time-related functions $u_{n, m-n}(t)$, $v_{n, m-n}(t)$ and $w_{n, m-n}(t)$ to the replace the functions $u_{n, m-n}, v_{n, m-n}$ and $w_{n, m-n}$ that are independent of the time in Equations (31)-(33). Therefore, the dynamic displacements are considered by the following shape functions.

The dynamic displacements are considered by the following shape functions:

$$
\begin{aligned}
& u_{0}(x, y, t)=\sum_{m=0}^{N} \sum_{n=0}^{m} u_{n, m-n}(t) x^{n} y^{n-m}, \\
& v_{0}(x, y, t)=\sum_{m=0}^{N} \sum_{n=0}^{m} v_{n, m-n}(t) x^{n} y^{n-m}, \\
& w_{0}(x, y, t)=\sum_{m=0}^{N} \sum_{n=0}^{m} w_{n, m-n}(t) x^{n} y^{n-m}
\end{aligned}
$$

It should be pointed out that $u_{n, m-n}, v_{n, m-n}$ and $w_{n, m-n}$ can represent the static curvature of the unsymmetric composite laminated plate, and $u_{n, m-n}(t), v_{n, m-n}(t)$ and $w_{n, m-n}(t)$ can represent the time-varying curvature of the unsymmetric cross-ply square composite laminated plate.

A low-order model for nonlinear dynamics is considered. Therefore, a finite number of degrees of freedom are selected from Equations (34)-(36), and the dynamic displacements are rewritten as

$$
\begin{gathered}
u_{0}=u_{1} x^{3}+u_{2} x y^{2}+u_{3} x, \\
v_{0}=v_{1} y^{3}+v_{2} y x^{2}+v_{3} y, \\
w_{0}=w_{1} x^{2}+w_{2} y^{2}
\end{gathered}
$$


Substituting Equations (37)-(39) into $U_{\text {total }}, T_{\text {total }}$ and $W_{\text {total }}$, Equation (19) can be expressed as a set of equations:

$$
\begin{aligned}
& a_{11} u_{1}+a_{12} u_{2}+a_{13} u_{3}+a_{14} v_{1}+a_{15} v_{2}+a_{16} v_{3}+a_{17} w_{1}+a_{18} w_{2}+a_{19} w_{1}^{2}+a_{110} w_{2}^{2}+a_{111} V+a_{112}=0 \text {, } \\
& a_{21} u_{1}+a_{22} u_{2}+a_{23} u_{3}+a_{24} v_{1}+a_{25} v_{2}+a_{26} v_{3}+a_{27} w_{1}+a_{28} w_{2}+a_{29} w_{1}^{2}+a_{210} w_{2}^{2}+a_{211} V+a_{212}=0 \text {, } \\
& a_{31} u_{1}+a_{32} u_{2}+a_{33} u_{3}+a_{34} v_{1}+a_{35} v_{2}+a_{36} v_{3}+a_{37} w_{1}+a_{38} w_{2}+a_{39} w_{1}^{2}+a_{310} w_{2}^{2}+a_{311} V+a_{312}=0 \text {, } \\
& a_{41} u_{1}+a_{42} u_{2}+a_{43} u_{3}+a_{44} v_{1}+a_{45} v_{2}+a_{46} v_{3}+a_{47} w_{1}+a_{48} w_{2}+a_{49} w_{1}^{2}+a_{410} w_{2}^{2}+a_{411} V+a_{412}=0 \text {, } \\
& a_{51} u_{1}+a_{52} u_{2}+a_{53} u_{3}+a_{54} v_{1}+a_{55} v_{2}+a_{56} v_{3}+a_{57} w_{1}+a_{58} w_{2}+a_{59} w_{1}^{2}+a_{510} w_{2}^{2}+a_{511} V+a_{512}=0 \\
& a_{61} u_{1}+a_{62} u_{2}+a_{63} u_{3}+a_{64} v_{1}+a_{65} v_{2}+a_{66} v_{3}+a_{67} w_{1}+a_{68} w_{2}+a_{69} w_{1}^{2}+a_{610} w_{2}^{2}+a_{611} V+a_{612}=0 \text {, } \\
& a_{71} u_{1}+a_{72} u_{2}+a_{73} u_{3}+a_{74} v_{1}+a_{75} v_{2}+a_{76} v_{3}+a_{77} w_{1}+a_{78} w_{2}+a_{79} w_{1}^{2}+a_{710} w_{2}^{2} \\
& +a_{711} w_{1} w_{2}+a_{712} V+a_{713}+a_{714} w_{1}^{3}+a_{715} w_{1} w_{2}^{2}+a_{716} w_{1} u_{1}+a_{717} w_{1} u_{2}+a_{718} w_{1} u_{3} \\
& +a_{719} w_{1} v_{1}+a_{720} w_{1} v_{2}+a_{721} w_{1} v_{3}+a_{722} w_{2} u_{2}+a_{723} w_{2} v_{2}+a_{724} \ddot{w}_{1}+a_{725} \ddot{w}_{2}+a_{726} \dot{w}_{1} \\
& +a_{727} \dot{w}_{2}+a_{728} \ddot{Y}+a_{729} V w_{1}+a_{730} V w_{2}=0 \text {, } \\
& a_{81} u_{1}+a_{82} u_{2}+a_{83} u_{3}+a_{84} v_{1}+a_{85} v_{2}+a_{86} v_{3}+a_{87} w_{1}+a_{88} w_{2}+a_{89} w_{1}^{2}+a_{810} w_{2}^{2} \\
& +a_{811} w_{1} w_{2}+a_{812} V+a_{813}+a_{814} w_{2}^{3}+a_{815} w_{2} w_{1}^{2}+a_{816} w_{2} u_{1}+a_{817} w_{2} u_{2}+a_{818} w_{2} u_{3} \\
& +a_{819} w_{2} v_{1}+a_{820} w_{2} v_{2}+a_{821} w_{2} v_{3}+a_{822} w_{1} u_{2}+a_{823} w_{1} v_{2}+a_{824} \ddot{w}_{1}+a_{825} \ddot{w}_{2}+a_{826} \dot{w}_{1} \\
& +a_{827} \dot{w}_{2}+a_{828} \ddot{Y}+a_{829} V w_{1}+a_{830} V w_{2}=0 \text {, }
\end{aligned}
$$

$$
\dot{V}+a_{91} V+a_{92} w_{1} \dot{w}_{1}+a_{93} w_{2} \dot{w}_{1}+a_{94} \dot{w}_{1}+a_{95} w_{1} \dot{w}_{2}+a_{96} w_{2} \dot{w}_{2}+a_{97} \dot{w}_{2}=0,
$$

Considering the transverse nonlinear oscillations, which are the primary motion, neglecting inertia terms $\ddot{u}_{0}$ and $\ddot{v}_{0}$, the displacement components $u_{1}, u_{2}, u_{3}, v_{1}, v_{2}$ and $v_{3}$ can be expressed in terms of $w_{1}$ and $w_{2}$ by solving Equations (40)-(45). Combining Equations (46)-(48), a three-degree-of-freedom nonlinear electromechanical equation can be obtained as follows:

$$
\begin{gathered}
\ddot{w}_{1}+c_{1} \dot{w}_{1}+k_{1} w_{1}+k_{2} w_{2}+N_{3}+V_{1} w_{1}+V_{2} w_{2}+V_{3}+b_{11} w_{1}^{2}+b_{12} w_{2}^{2}+b_{13} w_{1} w_{2} \\
+b_{14} w_{1}^{3}+b_{15} w_{2}^{3}+b_{16} w_{1}^{2} w_{2}+b_{17} w_{1} w_{2}^{2}=b_{18} \ddot{Y}, \\
\ddot{w}_{2}+c_{2} \dot{w}_{2}+k_{3} w_{1}+k_{4} w_{2}+N_{6}+V_{4} w_{1}+V_{5} w_{2}+V_{6}+b_{21} w_{1}^{2}+b_{22} w_{2}^{2}+b_{23} w_{1} w_{2} \\
+b_{24} w_{1}^{3}+b_{25} w_{2}^{3}+b_{26} w_{1}^{2} w_{2}+b_{27} w_{1} w_{2}^{2}=b_{28} \ddot{Y} \\
\dot{V}+b_{31} V+b_{32} w_{1} \dot{w}_{1}+b_{33} w_{2} \dot{w}_{1}+b_{34} \dot{w}_{1}+b_{35} w_{1} \dot{w}_{2}+b_{36} w_{2} \dot{w}_{2}+b_{37} \dot{w}_{2}=0 .
\end{gathered}
$$

In order to derive the dimensionless equations, the transformations of the variables and parameters are given as follows:

$$
\begin{aligned}
\bar{u}_{1}=u_{1}, \bar{u}_{2} & =L_{y}^{2} u_{2}, \bar{u}_{3}=L_{x}^{2} u_{3}, \bar{v}_{1}=v_{1}, \bar{v}_{2}=L_{x}^{2} v_{2}, \bar{v}_{3}=L_{y}^{2} v_{3} \\
\bar{w}_{1} & =L_{x} w_{1}, \bar{w}_{2}=L_{y} w_{2}, \bar{t}=\sqrt{k_{1}} t, \bar{\Omega}=\frac{\Omega}{\sqrt{k_{1}}} .
\end{aligned}
$$

Thus, Equations (49)-(51) can be rewritten in dimensionless forms:

$$
\begin{gathered}
\ddot{\bar{w}}_{1}+\bar{c}_{1} \dot{\bar{w}}_{1}+\bar{k}_{1} \bar{w}_{1}+\bar{k}_{2} \bar{w}_{2}+\bar{N}_{3}+\bar{V}_{1} \bar{w}_{1}+\bar{V}_{2} \bar{w}_{2}+\bar{V}_{3}+\bar{b}_{11} \bar{w}_{1}^{2}+\bar{b}_{12} \bar{w}_{2}^{2}+\bar{b}_{13} \bar{w}_{1} \bar{w}_{2} \\
+\bar{b}_{14} \bar{w}_{1}^{3}+\bar{b}_{15} \bar{w}_{2}^{3}+\bar{b}_{16} \bar{w}_{1}^{2} \bar{w}_{2}+\bar{b}_{17} \bar{w}_{1} \bar{w}_{2}^{2}=\bar{f} \cos (\bar{\Omega} \bar{t}), \\
\ddot{\bar{w}}_{2}+\bar{c}_{2} \dot{\bar{w}}_{2}+\bar{k}_{3} \bar{w}_{1}+\bar{k}_{4} \bar{w}_{2}+\bar{N}_{6}+\bar{V}_{4} \bar{w}_{1}+\bar{V}_{5} \bar{w}_{2}+\bar{V}_{6}+\bar{b}_{21} \bar{w}_{1}^{2}+\bar{b}_{22} \bar{w}_{2}^{2}+\bar{b}_{23} \bar{w}_{1} \bar{w}_{2} \\
+\bar{b}_{24} \bar{w}_{1}^{3}+\bar{b}_{25} \bar{w}_{2}^{3}+\bar{b}_{26} \bar{w}_{1}^{2} \bar{w}_{2}+\bar{b}_{27} \bar{w}_{1} \bar{w}_{2}^{2}=\bar{f} \cos (\bar{\Omega} \bar{t}), \\
\dot{\bar{V}}+\bar{b}_{31} \bar{V}+\bar{b}_{32} \bar{w}_{1} \dot{\bar{w}}_{1}+\bar{b}_{33} \bar{w}_{2} \dot{\bar{w}}_{1}+\bar{b}_{34} \dot{\bar{w}}_{1}+\bar{b}_{35} \bar{w}_{1} \dot{\bar{w}}_{2}+\bar{b}_{36} \bar{w}_{2} \dot{\bar{w}}_{2}+\bar{b}_{37} \dot{\bar{w}}_{2}=0 .
\end{gathered}
$$

where the coefficients $\bar{V}_{1}, \bar{V}_{2}, \bar{V}_{3}, \bar{V}_{4}, \bar{V}_{5}$ and $\bar{V}_{6}$ are associated with the output voltage $V$. 


\section{Analysis of Nonlinear Behaviors and Energy Harvesting}

In this section, the parameters of the unsymmetric cross-ply square composite laminated plate with the piezoelectric patch are set to be $E_{11}=146.95 \mathrm{GPa}, E_{22}=10.702 \mathrm{GPa}$, $G_{12}=6.977 \mathrm{GPa}, \alpha_{1}=5.028 \times 10^{-7}{ }^{\circ} \mathrm{C}^{-1}, \alpha_{2}=2.65 \times 10^{-5}{ }^{\circ} \mathrm{C}^{-1}, v_{12}=0.3, \rho_{\text {lam }}=1570 \mathrm{~kg} / \mathrm{m}^{3}$, $h=0.122 \mathrm{~mm}, L_{x}=150 \mathrm{~mm}, L_{y}=1500 \mathrm{~mm}, E_{11}^{E}=30.336 \mathrm{GPa}, E_{22}^{E}=15.857 \mathrm{GPa}, G_{12}^{E}=5.515 \mathrm{GPa}$, $h^{E}=0.3 \mathrm{~mm}, v_{12}^{E}=0.31, L_{1}=85 \mathrm{~mm}, L_{1}=57 \mathrm{~mm}, \rho_{\text {pie }}=5440 \mathrm{~kg} / \mathrm{m}^{3}, e_{31}=-210 \times 10^{-12}$ $\mathrm{C} / \mathrm{N}$ and $e_{32}=-210 \times 10^{-12} \mathrm{C} / \mathrm{N}$.

To present numerical results of the energy harvesting of the unsymmetric cross-ply square composite laminated plate with the piezoelectric patch, the sixth-order Runge-Kutta algorithm is utilized to numerically analyze Equations (53)-(55). For convenience in this study, the overbars in Equations (53)-(55) are dropped in the following analysis. The paper focuses on research of the influence of the foundation excitation amplitude $f$ on energy harvesting. The bifurcation diagrams, waveforms and phase portraits are presented to demonstrate energy harvesting.

The bifurcation diagrams are obtained in Figures 3 and 4. In the figure, $f$ is the external excitation amplitude, and $w$ is the transverse displacement which is the adopted position $(0.15,0.15)$ of the unsymmetric composite laminated plate, and $V$ is the voltage output. It can be seen from Figures 3 and 4 , with the excitation amplitude $f$ increasing, the motions of the unsymmetric composite laminated plate behave as a periodic motion, quasi-periodic motion and chaotic motion. The periodic motion behaves as a vibration, with a small amplitude around one of the two single-well chaotic attractors. The quasiperiodic motion behaves as the oscillation, with a large amplitude around one of the two single-well chaotic attractors. The chaotic motion behaves as an oscillation, with a large amplitude around the two-well chaos attractor. It should be pointed out that the two attractors actually correspond to two equilibrium positions. That is because the unsymmetric composite laminated plate demonstrates two equilibrium positions when the thermal stress is considered, as shown in Equations (12)-(13).

From Figure 3, it also can be found that the unsymmetric cross-ply square composite laminated plate with a piezoelectric patch has two stable positions. When the base excitation amplitude is in a certain range, a chaotic motion with a large amplitude between the two positions will occur. When the base excitation amplitude is out of a certain range, a periodic motion or chaotic motion with a small amplitude around one of the two positions will occur. Compared with Figure 3, the output voltage in Figure 4 also has two stable positions. When the base excitation amplitude is in a certain range, a chaotic motion with a large amplitude occurs, and the corresponding voltage output is relatively large. When the base excitation amplitude is out of a certain range, the voltage output is small. Hence, in order to improve the efficiency of the power generation, appropriate excitation amplitudes should be taken.

Moreover, in order to analyze the detailed motion status and energy harvesting of the unsymmetric cross-ply square composite laminated plate with a piezoelectric patch under different external excitation amplitudes, the dynamic essence and energy harvesting of the above motion region (e.g., Figure 3 ) is examined via the time domain response, phase portraits, voltage of the harvester and the Poincare map, as shown in Figures 5-13. 




Figure 3. The bifurcation diagram for displacement $w$ via the base excitation amplitude $f$.

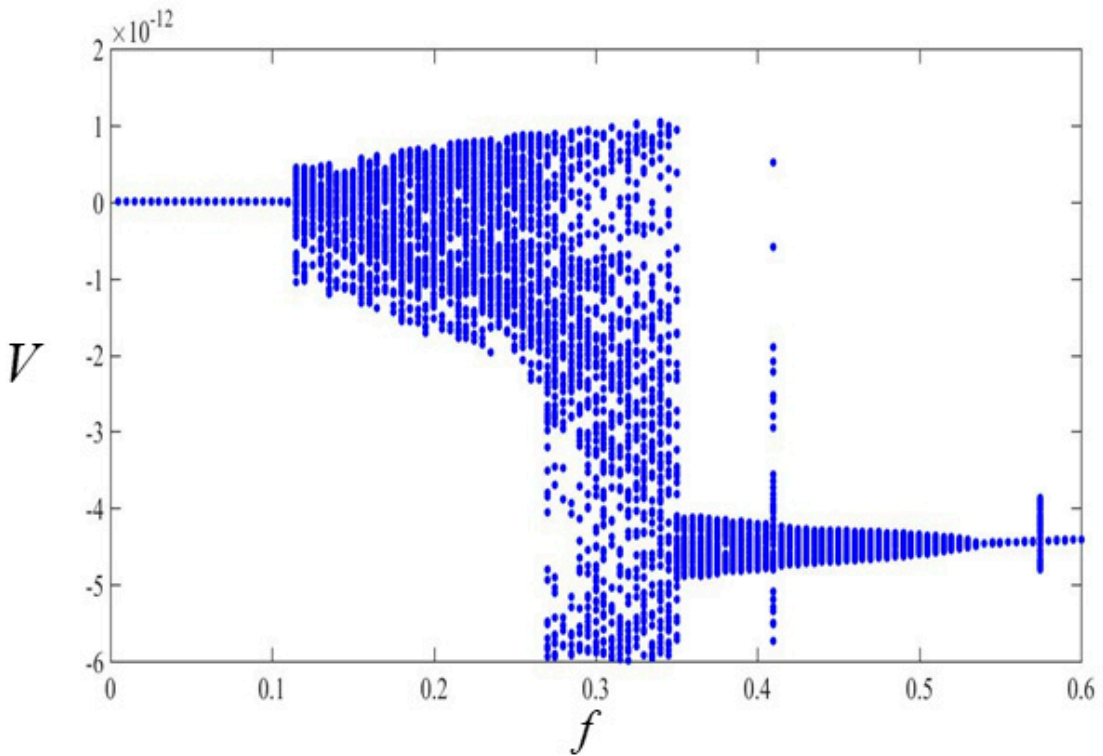

Figure 4. The bifurcation diagram for the voltage output $V$ via the base excitation amplitude $f$.

By analyzing the phase portrait and time history diagram in Figures $5-13$, two singlewell chaotic attractors and a two-well chaos attractor can be observed. In the figures, it is found that the motions behave as a periodic motion around one of the two singlewell chaotic attractors, a quasi-periodic motion around one of the two single-well chaotic attractors, a chaotic motion around one of the two single-well chaotic attractors, a chaotic motion around the two-well chaos attractor, a quasi-periodic motion around another one of the two single-well chaotic attractors and a periodic motion around another one of the two single-well chaotic attractors. 


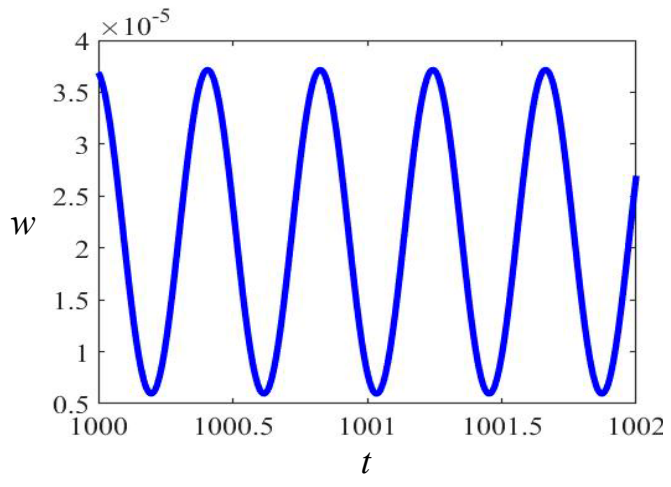

(a)

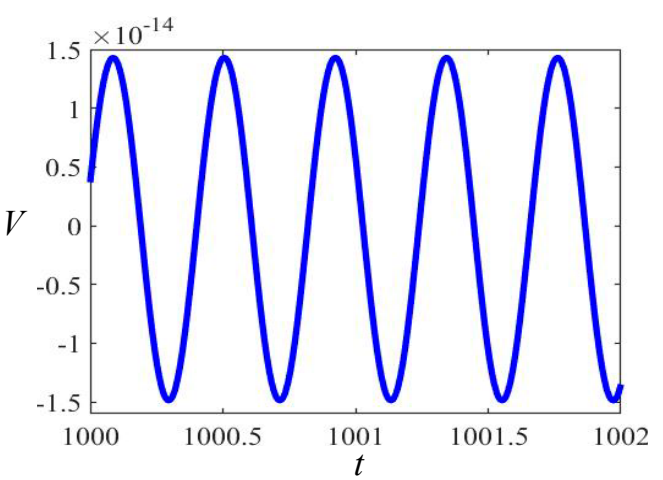

(c)

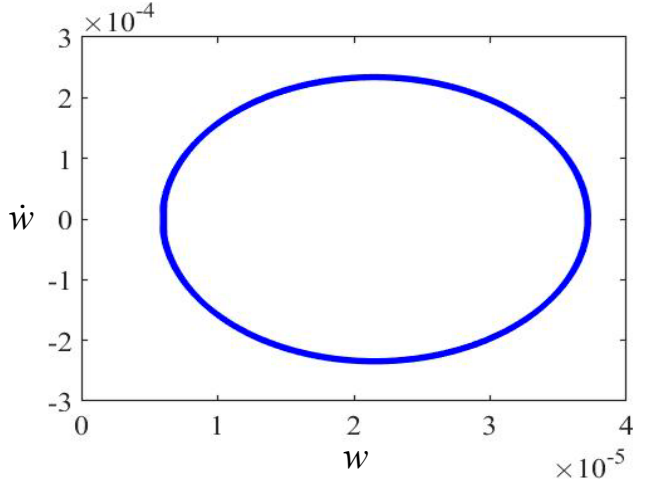

(b)

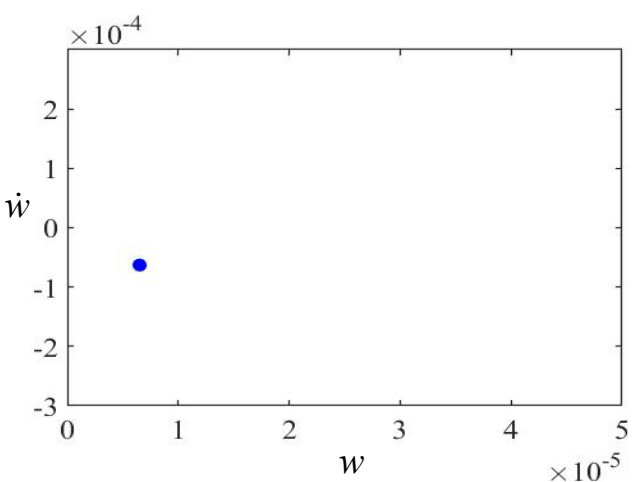

(d)

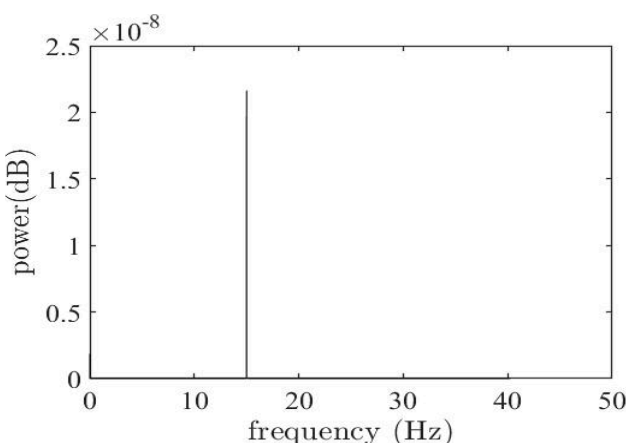

(e)

Figure 5. The periodic motion around one of the two single-well chaotic attractors when $f=0.01$. (a) The time history, (b) the phase portrait, (c) the voltage of the harvester, (d) the Poincare map and (e) the power spectrum.

From Figures 5-13, the influence of the excitation amplitude on the voltage of the harvester can be clearly identified. In Figure 5, because the base excitation amplitude is too small, the voltage output is weak, which is a small disturbance around the first stable position. Compared with Figure 5, the voltage output is significantly enhanced due to the increasing base excitation amplitude in Figure 6, which is a disturbance with a large amplitude near the first stable position. When the base excitation amplitude reaches a critical value, snap-through with sharp increasing amplitudes occurs in the process of voltage output, as shown in Figure 7 . When the base excitation amplitude is in a certain range, constant snap-through with a large amplitude occurs in the process of voltage output, which represents the extremely powerful power generation capacity, as shown in Figures 8-10. From Figures 8-10, it can be found that the output voltage oscillates around two stable positions with a large amplitude, which means a significantly higher generation efficiency. When the base excitation amplitude is beyond the scope, which is shown in Figure 4, the output voltage oscillates near the second stable position with sharp decreasing amplitudes, which is shown in Figure 11. Figure 11 shows almost the same generation 
efficiency as Figure 6. Similar to Figure 5, when the base excitation amplitude is too large, the voltage output is again weak, which is a small disturbance around the second stable position in Figures 12 and 13.

By comparing the figures of each group, it can be seen that, when the motions go around single-well attractor, the amplitude of the response is relatively small, while when the motions go around a double-well attractor, the amplitude of the response is quite large. In order to improve the efficiency of power generation, we try to make the motions of the system happen around the double-well attractor.

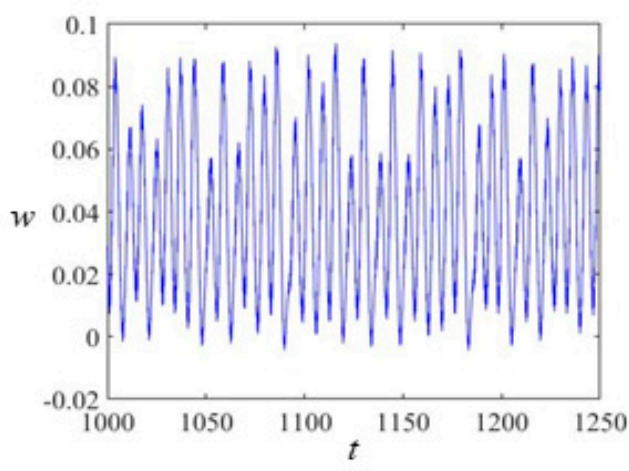

(a)

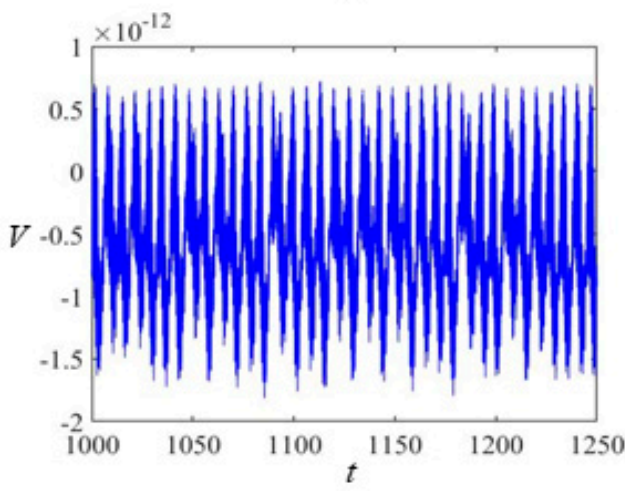

(c)

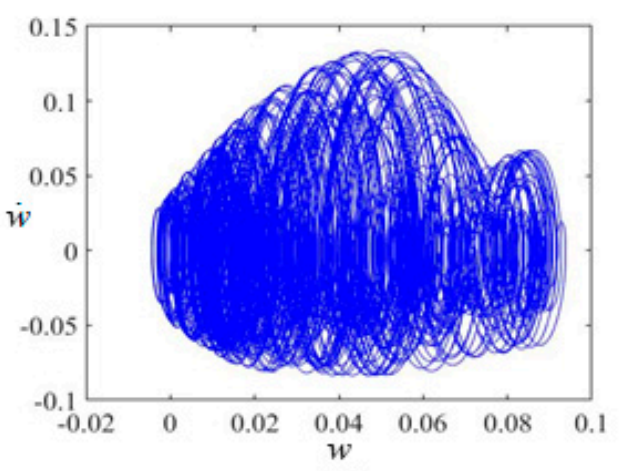

(b)



(d)

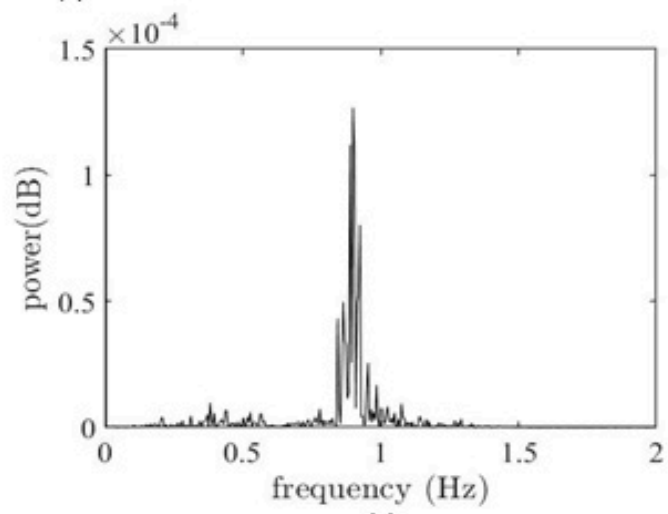

(e)

Figure 6. The chaotic motion around one of the two single-well chaotic attractors $f=0.2$. (a) The time history, (b) the phase portrait, (c) the voltage of the harvester, (d) the Poincare map and (e) the power spectrum. 


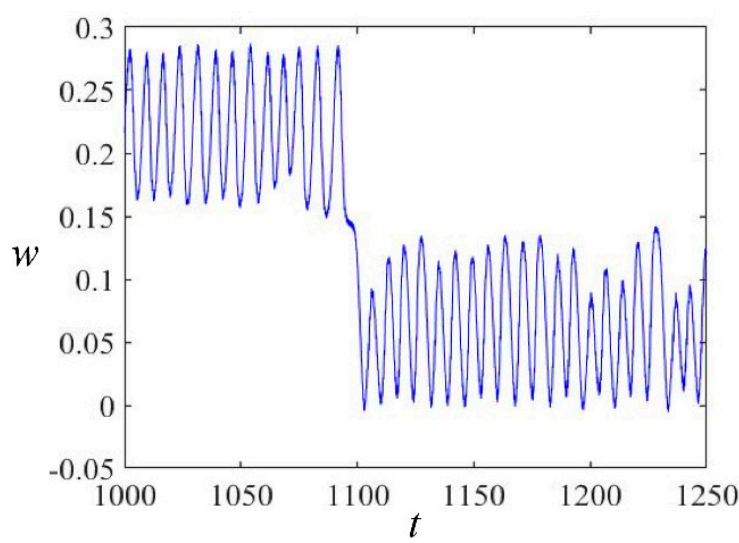

(a)

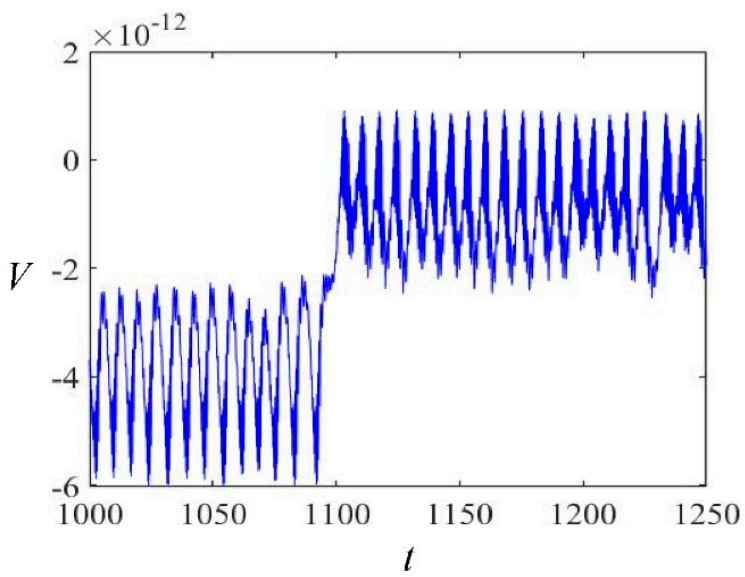

(c)

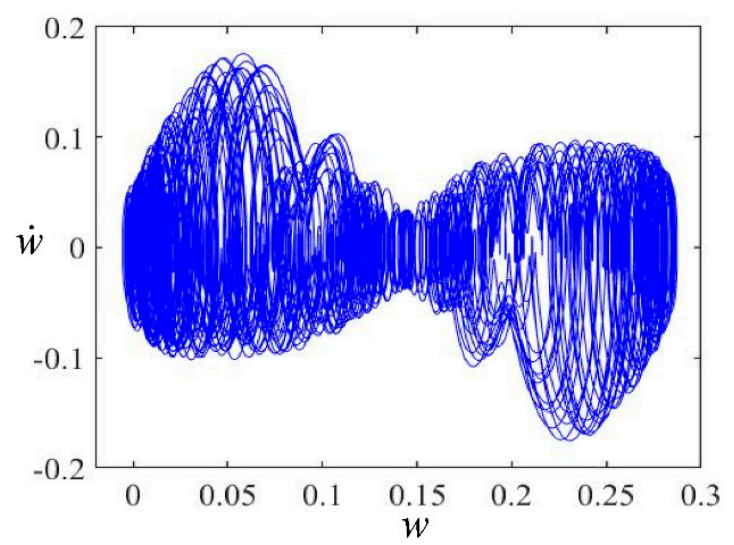

(b)

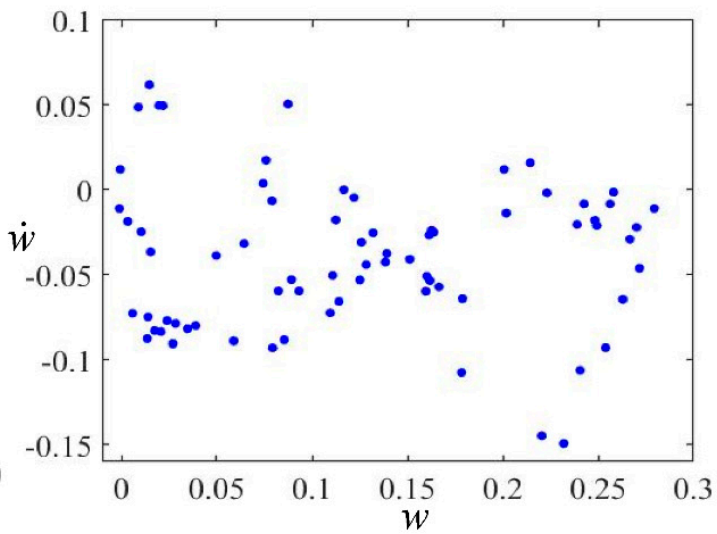

(d)

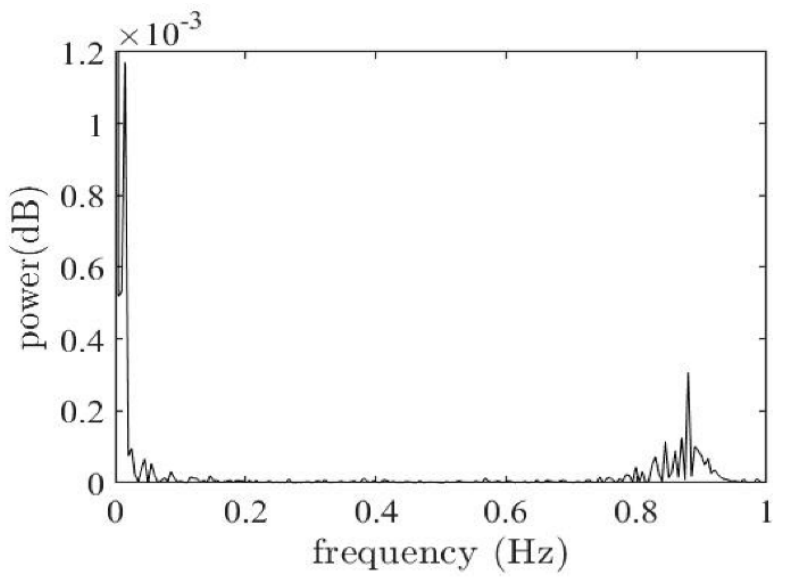

(e)

Figure 7. The chaotic motion and one-way snap-through around the two-well chaos attractor $f=0.27$. (a) The time history, (b) the phase portrait, (c) the voltage of the harvester, (d) the Poincare map and (e) the power spectrum. 


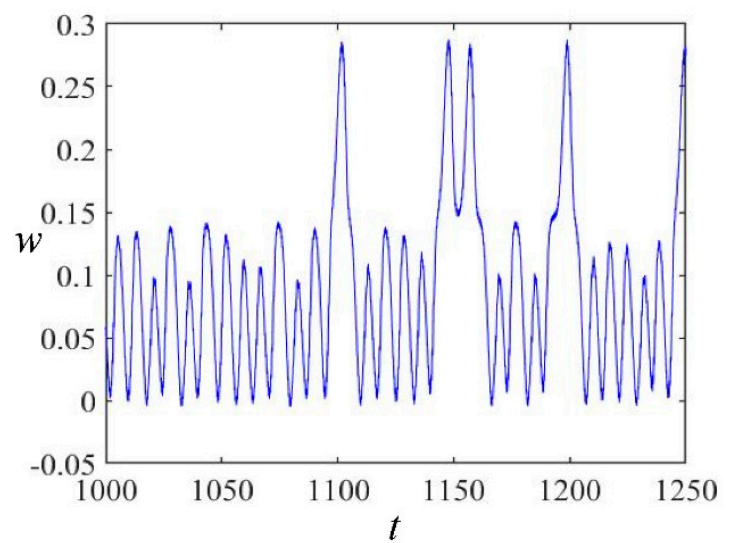

(a)

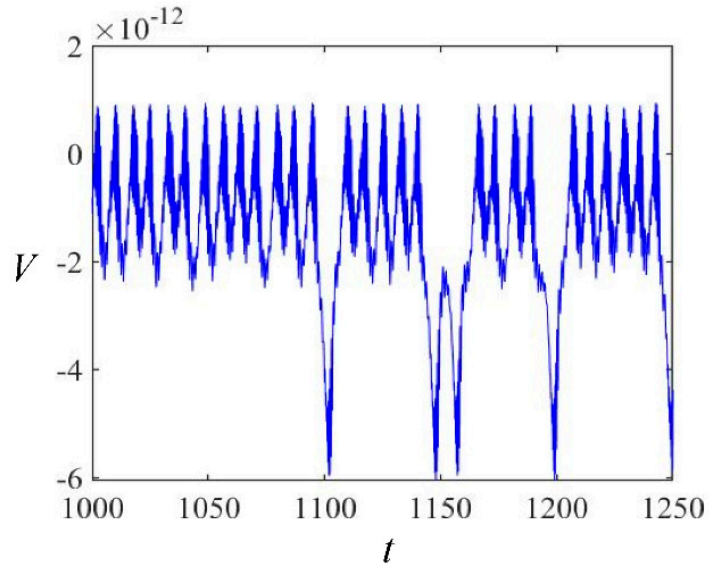

(c)

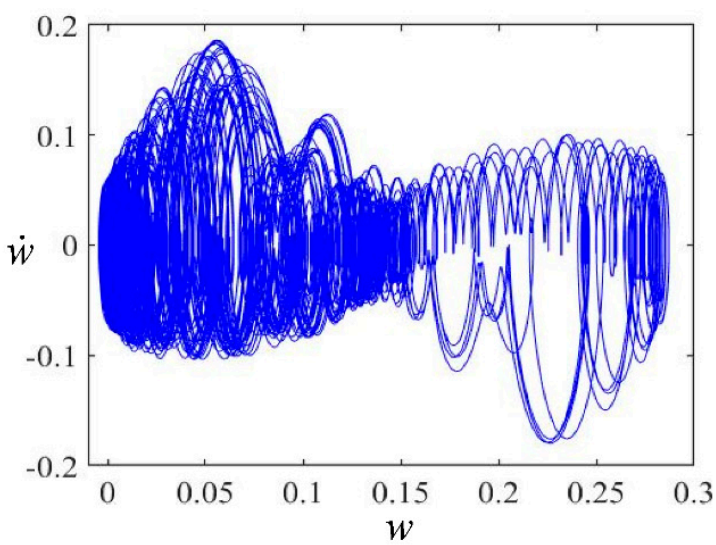

(b)

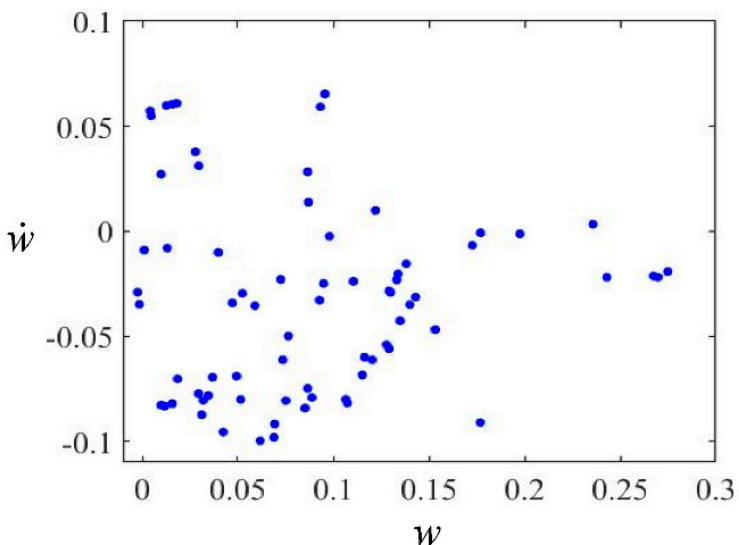

(d)

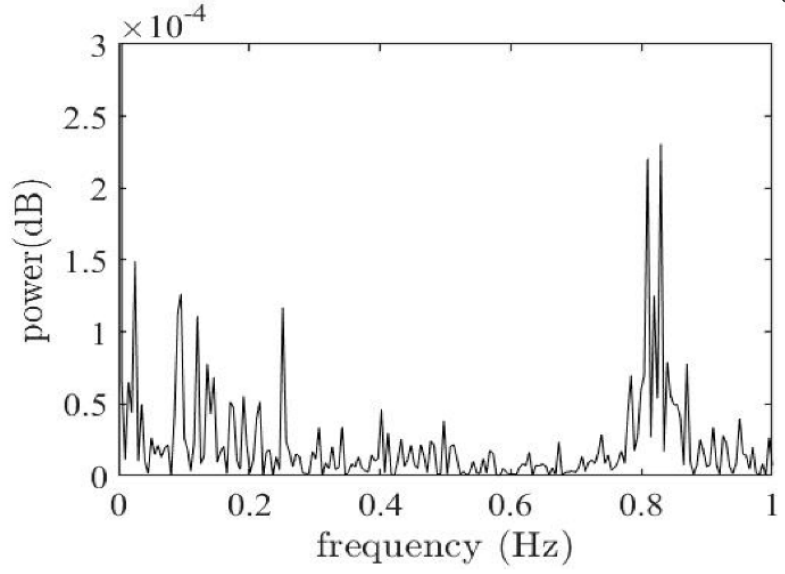

(e)

Figure 8. The chaotic motion and multiple-way snap-through around the two-well chaos attractor $f=0.28$. (a) The time history, (b) the phase portrait, (c) the voltage of the harvester, (d) the Poincare map and (e) the power spectrum. 


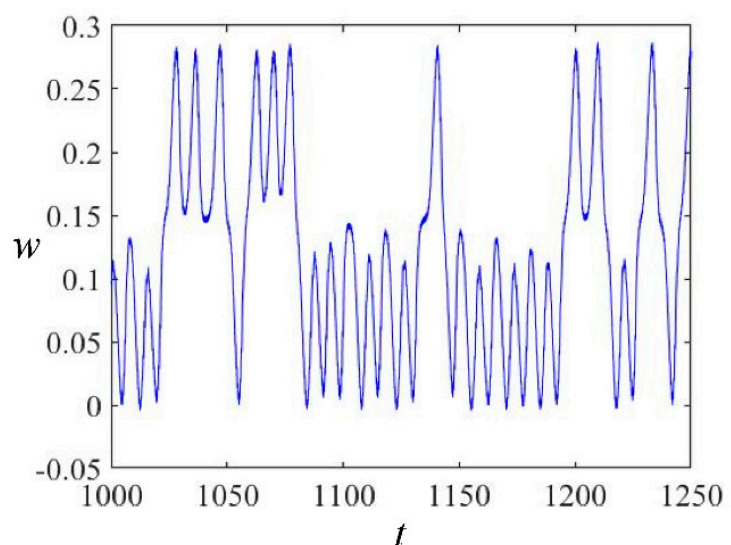

(a)

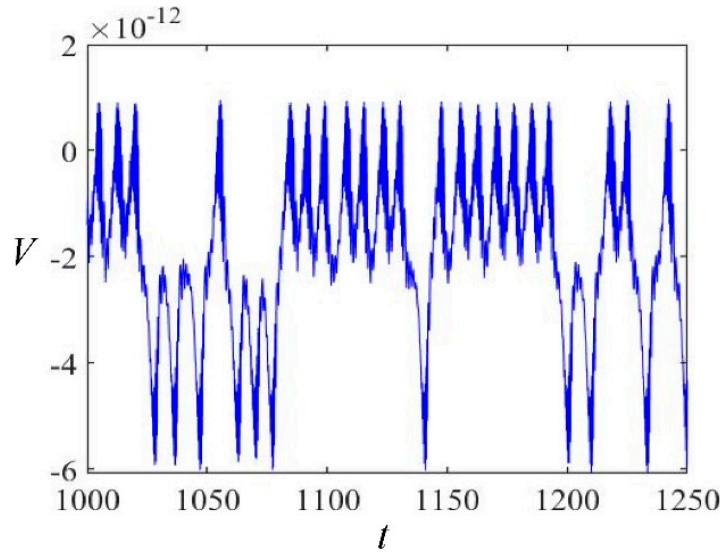

(c)

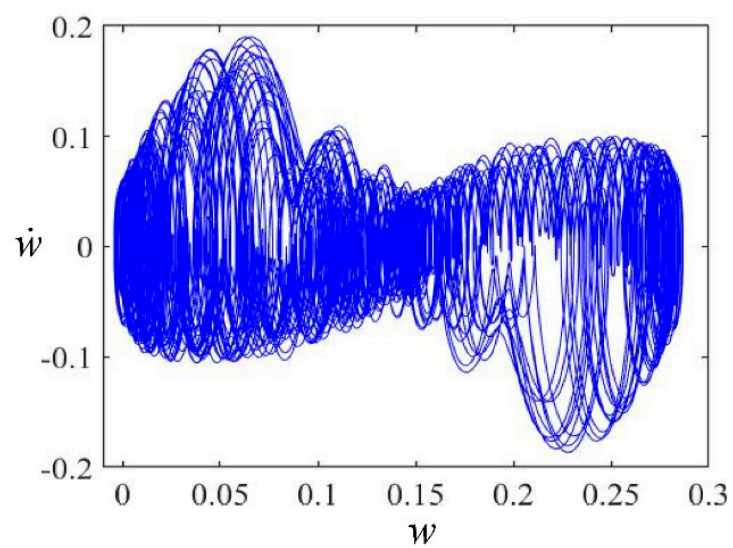

(b)

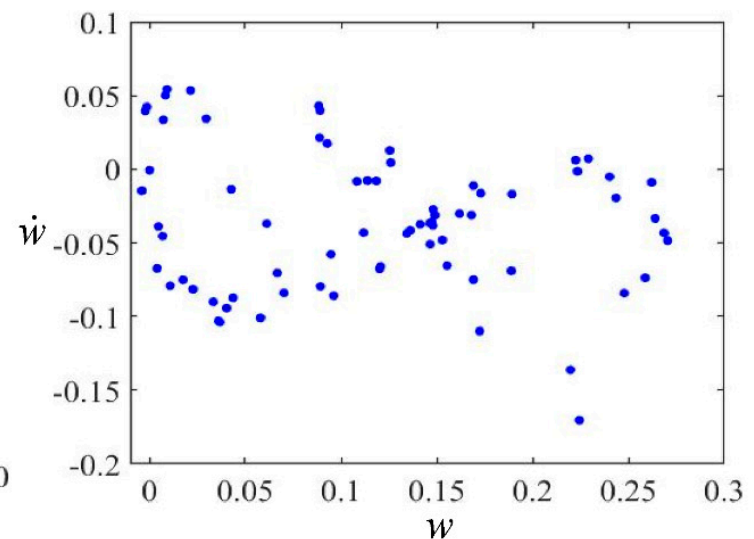

(d)

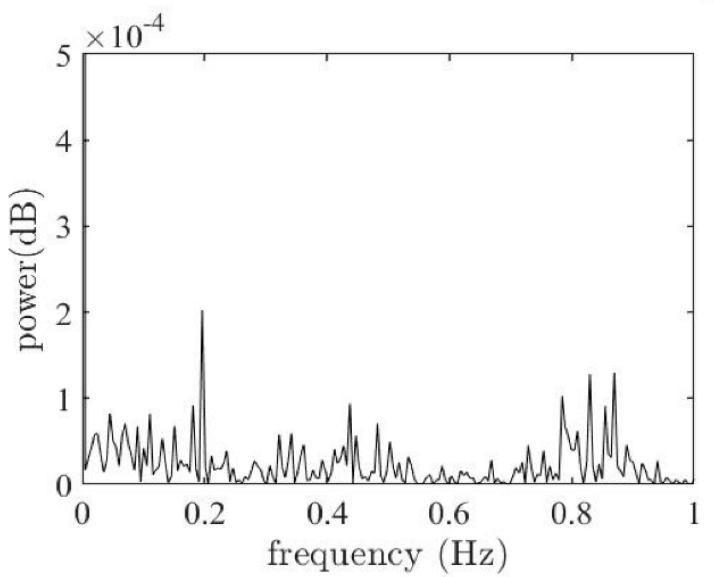

(e)

Figure 9. The chaotic motion and multiple-way snap-through around the two-well chaos attractor $f=0.29$. (a) The time history, (b) the phase portrait, (c) the voltage of the harvester, (d) the Poincare map and (e) the power spectrum. 


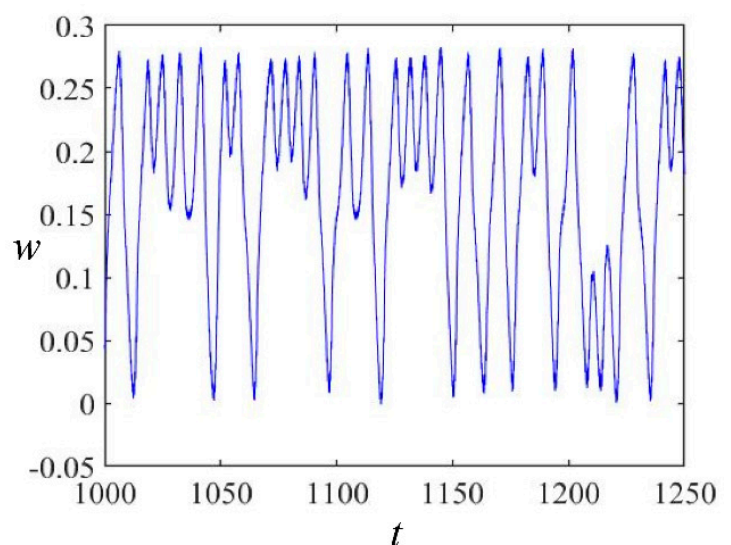

(a)



(c)

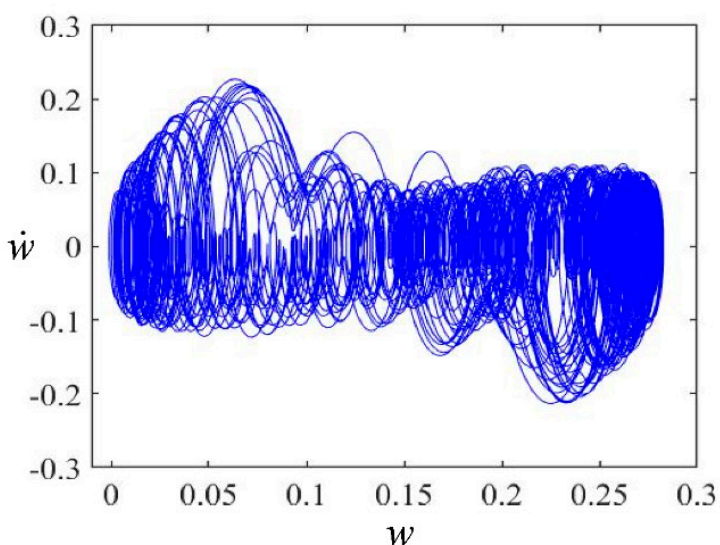

(b)



(d)

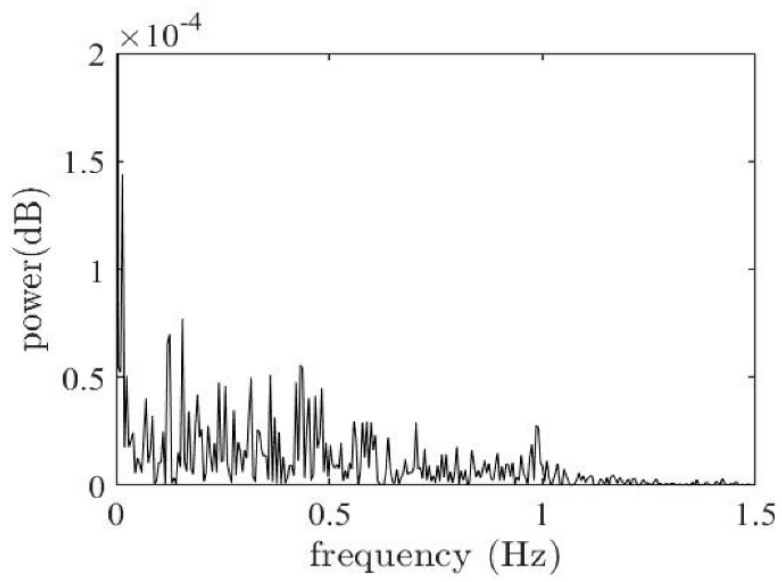

(e)

Figure 10. The chaotic motion and constant snap-through around the two-well chaos attractor $f=0.35$. (a) The time history, (b) the phase portrait, (c) the voltage of the harvester, (d) the Poincare map and (e) the power spectrum. 


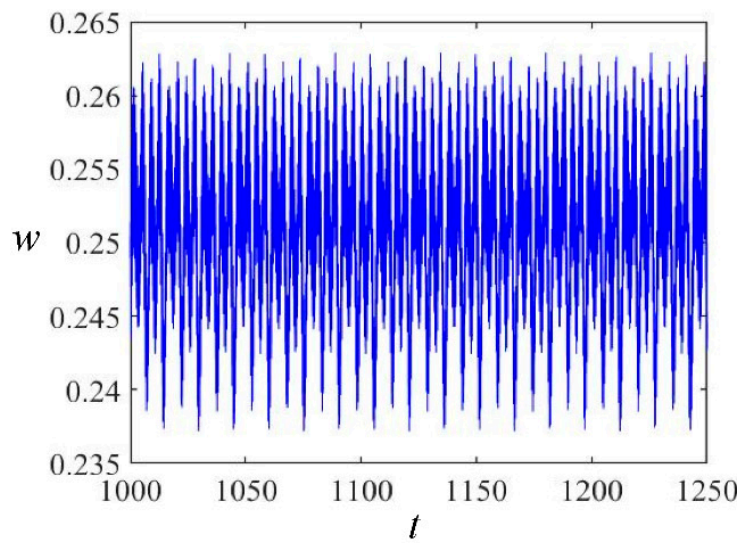

(a)

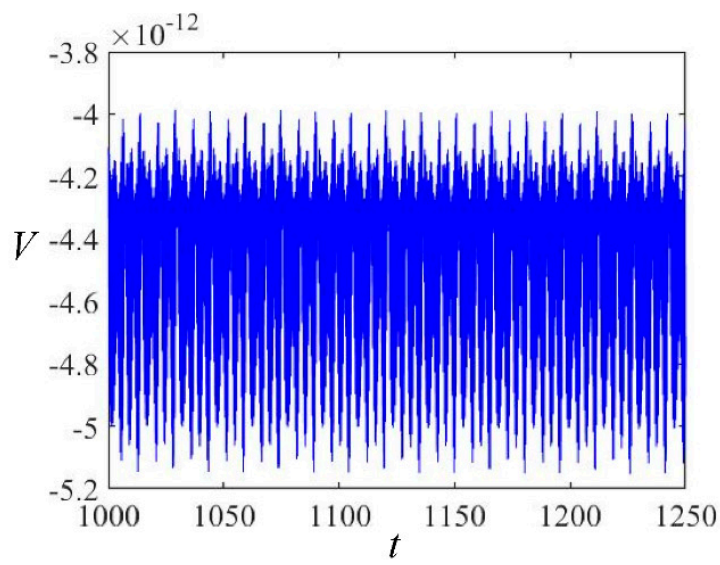

(c)

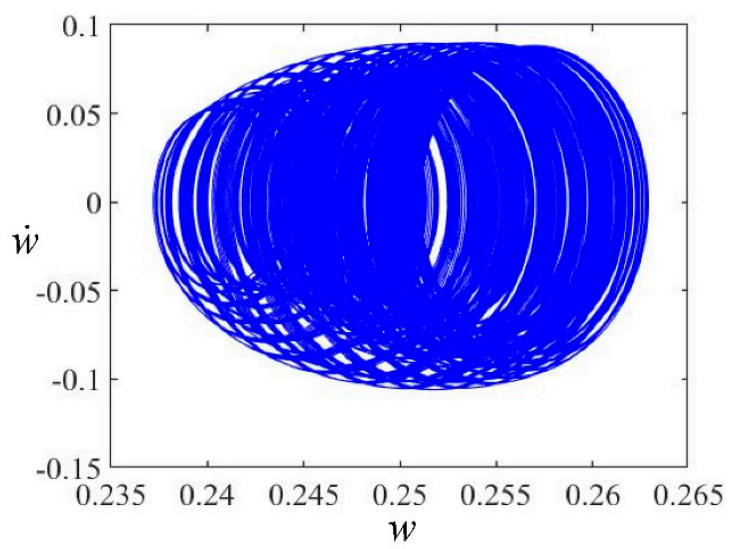

(b)

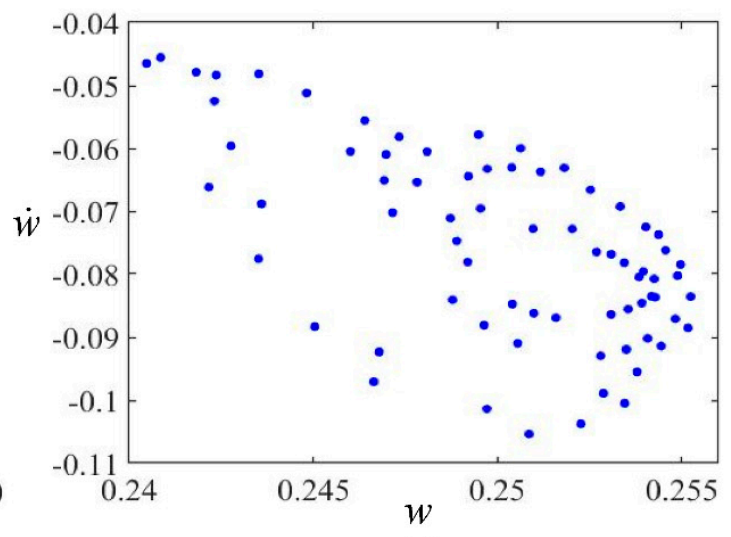

(d)

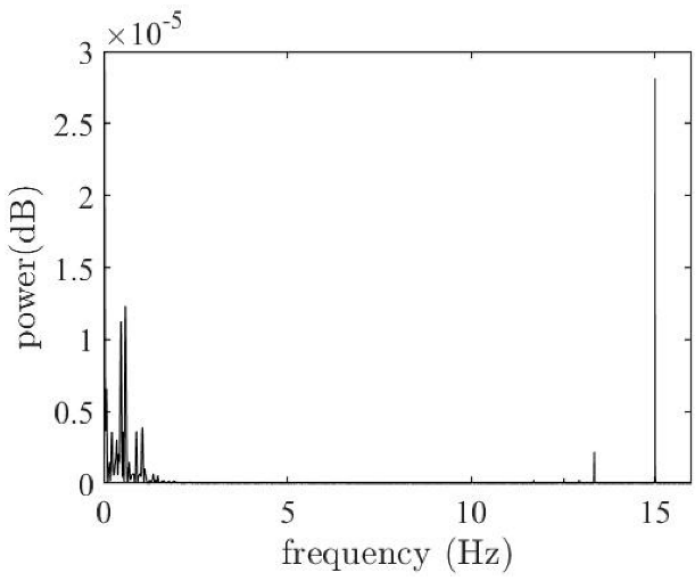

(e)

Figure 11. The chaotic motion around another one of the two single-well chaotic attractors $f=0.37$. (a) The time history, (b) the phase portrait, (c) the voltage of the harvester, (d) the Poincare map and (e) the power spectrum. 


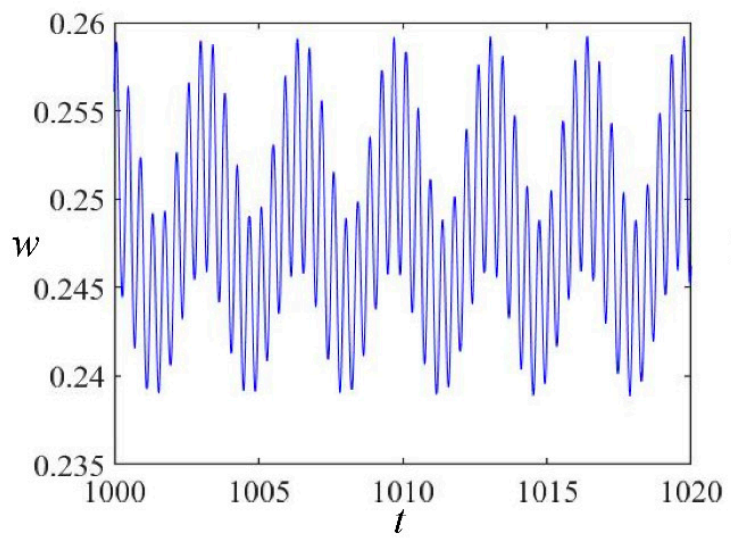

(a)

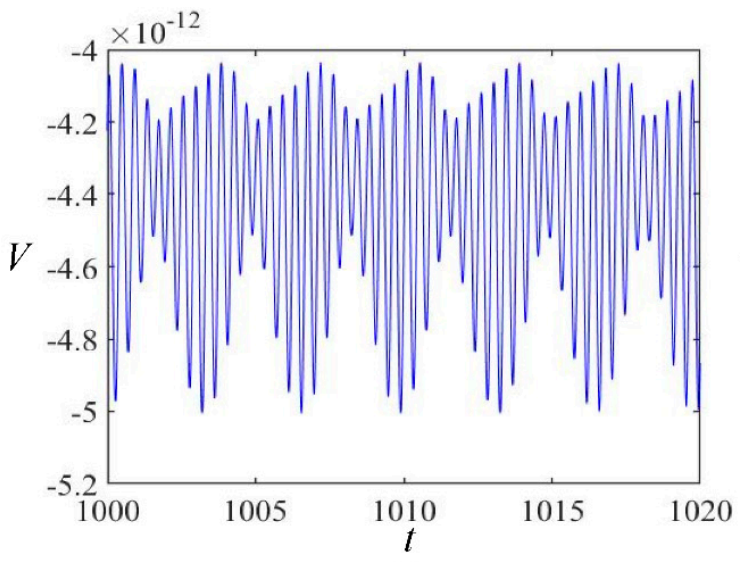

(c)

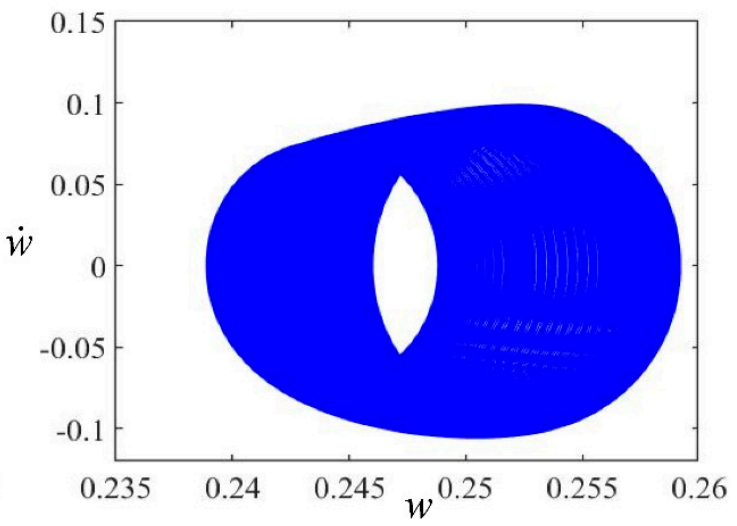

(b)

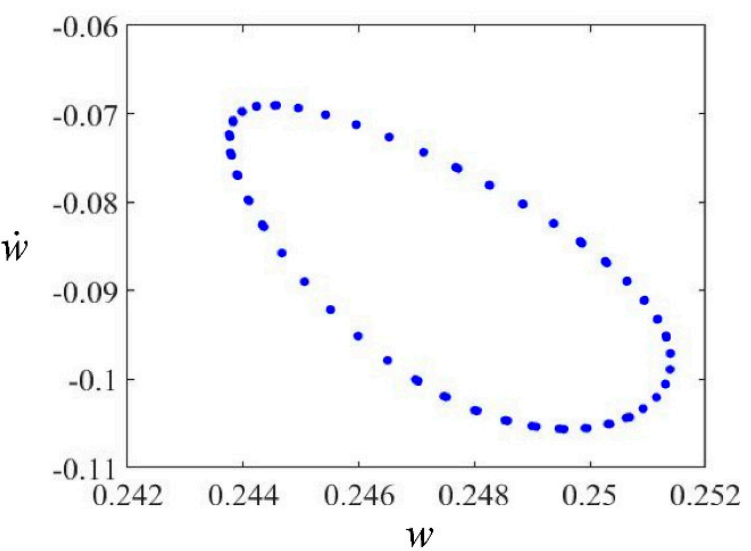

(d)



(e)

Figure 12. The quasi-periodic motion around another one of the two single-well chaotic attractors $f=0.45$. (a) The time history, (b) the phase portrait, (c) the voltage of the harvester, (d) the Poincare map and (e) the power spectrum. 




(a)

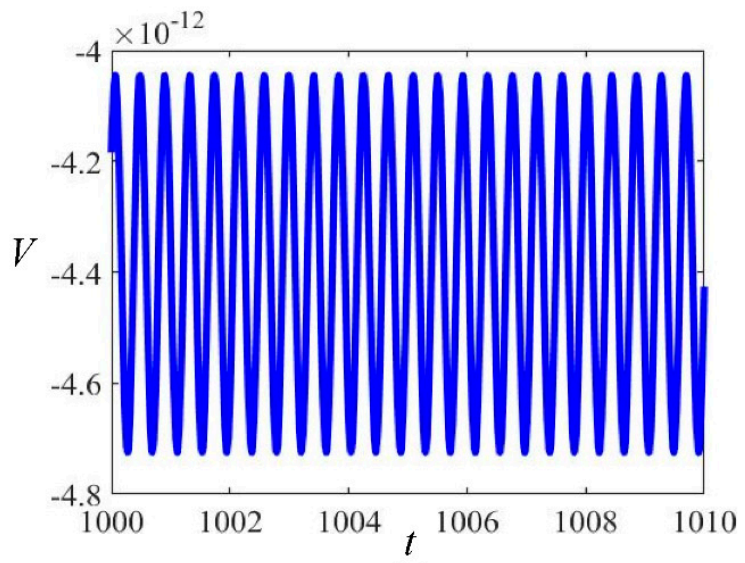

(c)



(b)



(d)

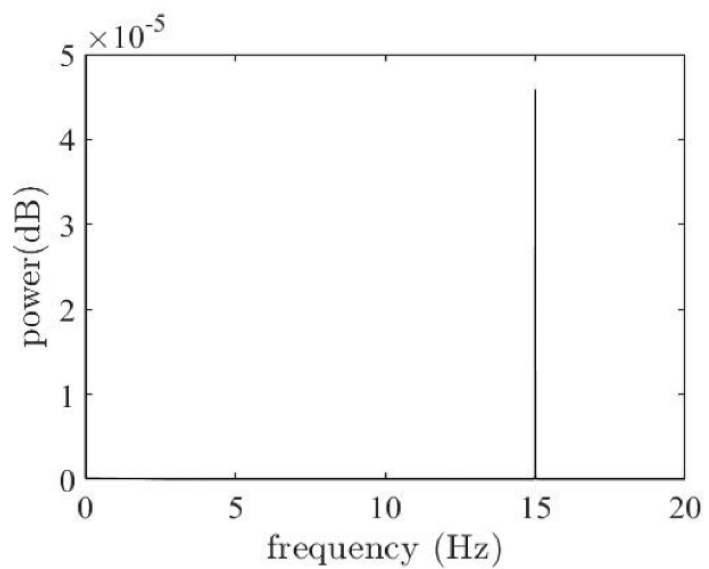

(e)

Figure 13. The periodic motion around another one of the two single-well chaotic attractors $f=0.56$. (a) The time history, (b) the phase portrait, (c) the voltage of the harvester, (d) the Poincare map and (e) the power spectrum.

Based on the above analysis, it can be concluded that, with the change of the base excitation amplitude, the complex nonlinear dynamics of the system behave as a periodic motion, quasi-periodic motion and chaotic motion. When the base excitation amplitude is in a specific scope, snap-through with a large amplitude appears accompanying a chaotic motion. It is based on these complex nonlinear dynamic behaviors that we can determine how to make the energy-harvesting device have the highest power generation efficiency and the strongest power generation capacity. By adjusting the base excitation amplitude, the 
response of the system is made in a range with large amplitudes to make sure the occurrence of snap-through and chaotic motion. Snap-through with a large amplitude appearing accompanying chaotic motion guarantees the highest power generation efficiency and the strongest power generation capacity.

The unsymmetric cross-ply square composite laminated plate subjected to thermal stress can actually be called a kind of bistable composite shell structure. That is to say, this kind of bistable energy-harvesting device has a broad application prospect in combination with morphing aircraft, large deployable antenna and a solar panel, which are very likely to have nonlinear vibrations.

\section{Conclusions}

The nonlinear behaviors and energy harvesting of an unsymmetric cross-ply square composite laminated plate with a piezoelectric patch was studied. The nonlinear electromechanical coupling equation of motion was derived. The influence of the external excitation amplitude on nonlinear behaviors and energy harvesting was analyzed. The main conclusions can be drawn as follows:

(1) Compared with the general composite laminated plate, the unsymmetric crossply square composite laminated plates subjected to thermal stress have two equilibrium positions, which can lead to snap-through with a large amplitude, thus greatly improving the efficiency of power generation and greatly enhancing the power generation capacity.

(2) With the change of the base excitation amplitude, the motions of the unsymmetric cross-ply square composite laminated plate demonstrate periodic motion, quasi-periodic motion and chaotic motion.

(3) When the unsymmetric cross-ply square composite laminated plate is subjected to external excitation, two single-well chaotic attractors and a two-well chaos attractor may coexist. When the excitation amplitude is in a specific scope, the motions of the plate around the double-well attractor (meaning the snap-through occurs), at this moment, the unsymmetric cross-ply square composite laminated plate with piezoelectric patch can obtain the highest power generation efficiency and the strongest power generation capacity.

(4) The unique nonlinear characteristics of the designed structure make its own excellent power generation efficiency. Moreover, the power generation efficiency is optimal when the excitation amplitude is in a certain range.

(5) The unsymmetric cross-ply square composite laminated plate subjected to thermal stress can actually be called a kind of bistable composite shell structure that has two stable equilibrium positions. Due to snap-through, bistable composite shell structures are admittedly ideal materials for energy-harvesting devices.

Actually, the conclusions were mainly about the bi-stability of the unsymmetric composite laminated plate subjected to thermal stress, which had two stable equilibrium positions. The reason why this kind of structure is important for energy harvesting devices is actually the snap-through between the two stable equilibrium positions.

Author Contributions: Conceptualization, G.J. and T.D.; methodology, T.D.; software, T.D.; validation, T.D.; formal analysis, G.J. and T.D.; investigation, T.D.; resources, T.D. and Z.G.; data curation, T.D. and Z.G.; writing—original draft preparation, G.J., T.D. and Z.G.; writing—review and editing, G.J., T.D. and Z.G.; visualization, T.D.; supervision, T.D.; project administration, G.J., T.D. and Z.G.; funding acquisition, G.J. and Z.G. All authors have read and agreed to the published version of the manuscript.

Funding: This study was financially supported by the National Natural Science Foundation of China (Project no. 12002100), Beijing Natural Science Foundation (Project no. 8202015), the State Key Laboratory of Mechanical System and Vibration (Project no. MSV202108) and Open Research Fund Program of Beijing Key Laboratory of Performance Guarantee on Urban Rail Transit Vehicles (no. PGU2020K005).

Institutional Review Board Statement: Not applicable.

Informed Consent Statement: Not applicable. 
Data Availability Statement: The study did not report any data.

Conflicts of Interest: The authors declare no conflict of interest.

\section{References}

1. Liu, M.Y.; Tai, W.C.; Zuo, L. Toward broadband vibration energy harvesting via mechanical motion-rectification induced inertia nonlinearity. Smart Mater. Struct. 2018, 27, 075022. [CrossRef]

2. Pan, Y.; Liu, F.W.; Jiang, R.J.; Tu, Z.W.; Zuo, L. Modeling and onboard test of an electromagnetic energy harvester for railway cars. Appl. Energy 2019, 250, 568-581. [CrossRef]

3. Pillatsch, P.; Yeatman, E.M.; Holmes, A.S. Real world testing of a piezoelectric rotational energy harvester for human motion. J. Phys. Conf. Ser. 2013, 476, 012010. [CrossRef]

4. Shafer, M.W.; MacCurdy, R.; Shipley, J.R.; Winkler, D.; Guglielmo, C.G.; Garcia, E. The case for energy harvesting on wildlife in flight. Smart Mater. Struct. 2015, 24, 025031. [CrossRef]

5. Wang, J.L.; Geng, L.F.; Yang, K.; Zhao, L.Y.; Wang, F.; Yurchenko, D. Dynamics of the double-beam piezo-magneto-elastic nonlinear wind energy harvester exhibiting galloping-based vibration. Nonlinear Dyn. 2020, 100, 1963-1983. [CrossRef]

6. Orrego, S.; Shoele, K.; Ruas, A.; Doran, K.; Brett, C.; Rajat, M.; Kang, S.H. Harvesting ambient wind energy with an inverted piezoelectric flag. Appl. Energy 2017, 194, 212-222. [CrossRef]

7. Orazov, B.; O'Reilly, O.M.; Savaş, S. On the dynamics of a novel ocean wave energy converter. J. Sound Vib. 2010, 329, 5058-5069. [CrossRef]

8. Li, M.; Jing, X.J. Novel tunable broadband piezoelectric harvesters for ultralow-frequency bridge vibration energy harvesting. Appl. Energy 2019, 255, 113829. [CrossRef]

9. White, E.B. Energy-harvesting devices: Beyond the battery. Nat. Nanotechnol. 2008, 3, 71-72. [CrossRef]

10. Qiu, J.; Chen, H.J.; Wen, Y.M.; Li, P. Magnetoelectric and electromagnetic composite vibration energy harvester for wireless sensor networks. J. Appl. Phys. 2015, 117, 1-4. [CrossRef]

11. Asai, T.; Araki, Y.; Ikago, K. Energy harvesting potential of tuned inertial mass electromagnetic transducers. Mech. Syst. Sig. Process. 2017, 84, 659-672. [CrossRef]

12. Naruse, Y.; Matsubara, N.; Mabuchi, K.; Izumi, M.; Suzuki, S. Electrostatic micro power generation from low-frequency vibration such as human motion. J. Micromech. Microeng. 2009, 19, 094002. [CrossRef]

13. Basset, P.; Galayko, D.; Paracha, A.M.; Marty, F.; Dudka, A.; Bourouina, T. A batch-fabricated and electret-free silicon electrostatic vibration energy harvester. J. Micromech. Microeng. 2009, 19, 115025. [CrossRef]

14. Hoffmann, D.; Folkmer, B.; Manoli, Y. Fabrication. Characterization and modelling of electrostatic micro-generators. J. Micromech Microeng. 2009, 19, 094001. [CrossRef]

15. Khan, U.; Kim, S.W. Triboelectric nanogenerators for blue energy harvesting. ACS Nano 2016, 10, 6429-6432. [CrossRef]

16. Chen, R.W.; Ren, L.; Xia, H.K.; Yuan, X.W.; Liu, X.J. Energy harvesting performance of a dandelion-like multi-directional piezoelectric vibration energy harvester. Sens. Actuators A Phys. 2015, 230, 1-8. [CrossRef]

17. Jung, I.; Shin, Y.H.; Kim, S.; Choi, J.Y.; Kang, C.Y. Flexible piezoelectric polymer-based energy harvesting system for roadway applications. Appl. Energy 2017, 197, 222-229. [CrossRef]

18. Tang, X.; Lin, T.; Zuo, L. Design and optimization of a tubular linear electromagnetic vibration energy harvester. IEEE/ASME Trans. Mechatron. 2014, 19, 615-622. [CrossRef]

19. Amirtharajah, R.; Chandrakasan, A.P. Self-Powered signal processing using vibration-based power generation. IEEE J. Solid-State Circuits 1998, 33, 687-695. [CrossRef]

20. Mann, B.P.; Owens, B.A. Investigations of a nonlinear energy harvester with a bistable potential well. J. Sound Vib. 2010, 329, 1215-1226. [CrossRef]

21. Poulin, G.; Sarraute, E.; Costa, F. Generation of electrical energy for portable devices: Comparative study of an electromagnetic and a piezoelectric system. Sens. Actuators A Phys. 2004, 116, 461-471. [CrossRef]

22. Erturk, A.; Inman, D.J. An experimentally validated bimorph cantilever model for piezoelectric energy harvesting from base excitations. Smart Mater. Struct. 2009, 18, 025009. [CrossRef]

23. Anton, S.R.; Sodano, H.A. A review of power harvesting using piezoelectric materials. Smart Mater. Struct. 2007, 16, R1-R21. [CrossRef]

24. Ferrari, M.; Ferrari, V.; Guizzetti, M. Piezoelectric multifrequency energy converter for power harvesting in autonomous microsystems. Sens. Actuators A Phys. 2008, 142, 329-335. [CrossRef]

25. Leland, E.S.; Wright, P.K. Resonance tuning of piezoelectric vibration energy scavenging generators using compressive axial preload. Smart Mater. Struct. 2006, 15, 1413-1420. [CrossRef]

26. Dutoit, N.E.; Wardle, B.L. Experimental verification of models for microfabricated piezoelectric vibration energy harvesters. AIAA 2007, 45, 1126-1137. [CrossRef]

27. Wei, C.F.; Jing, X.J. A comprehensive review on vibration energy harvesting: Modelling and realization. Renew. Sustain. Energy Rev. 2017, 74, 1-18. [CrossRef]

28. Yildirim, T.; Ghayesh, M.H.; Li, W.H.; Alici, G. A review on performance enhancement techniques for ambient vibration energy harvesters. Renew. Sustain. Energy Rev. 2017, 71, 435-449. [CrossRef] 
29. Challa, V.R.; Prasad, M.G.; Shi, Y.; Fisher, F.T. A vibration energy harvesting device with bidirectional resonance frequency tunability. Smart Mater. Struct. 2008, 17, 015035. [CrossRef]

30. Youngsman, J.M.; Luedeman, T.; Morris, D.J.; Anderson, M.J.; Bahr, D.F. A model for an extensional mode resonator used as a frequency-adjustable vibration energy harvester. J. Sound Vib. 2010, 329, 277-288. [CrossRef]

31. Daqaq, M.F.; Stabler, C.; Qaroush, Y.; Seuaciuc-Osório, T. Investigation of power harvesting via parametric excitations. J. Intell. Mater. Syst. Struct. 2009, 20, 545-557. [CrossRef]

32. Yildirim, T.; Ghayesh, M.H.; Searle, T.; Li, W.; Alici, G. A parametrically broadband nonlinear energy harvester. J. Energy Resour. ASME 2017, 139, 032001. [CrossRef]

33. Yuan, T.C.; Yang, J.; Chen, L.Q. Nonlinear dynamics of a circular piezoelectric plate for vibratory energy harvesting. Commun. Nonlinear Sci. 2018, 59, 651-656. [CrossRef]

34. Jin, Y.; Hou, S.; Yang, T.Z. Cascaded essential nonlinearities for enhanced vibration suppression and energy harvesting. Nonlinear Dyn. 2021, 103, 1427-1438. [CrossRef]

35. Moon, F.C.; Holmes, P.J. A magnetoelastic strange attractor. J. Sound Vib. 1979, 65, 275-296. [CrossRef]

36. Stanton, S.C.; Owens, B.A.M.; Mann, B.P. Harmonic balance analysis of the bistable piezoelectric inertial generator. J. Sound Vib. 2012, 331, 3617-3627. [CrossRef]

37. Erturk, A.; Inman, D.J. Broadband piezoelectric power generation on high-energy orbits of the bistable duffing oscillator with electromechanical coupling. J. Sound Vib. 2011, 330, 2339-2353. [CrossRef]

38. Zhu, Y.; Zu, J.W. Enhanced buckled-beam piezoelectric energy harvesting using midpoint magnetic force. Appl. Phys. Lett. 2013, 103, 041905. [CrossRef]

39. Zhou, Z.; Qin, W.; Zhu, P. A broadband quad-stable energy harvester and its advantages over bistable harvester: Simulation and experiment verification. Mech. Syst. Signal Process. 2017, 84, 158-168. [CrossRef]

40. Wang, C.; Zhang, Q.C.; Wang, W.; Feng, J.J. A low-frequency, wideband quad-stable energy harvester using combined nonlinearity and frequency up-conversion by cantilever-surface contact. Mech. Syst. Signal Process. 2018, 112, 305-318. [CrossRef]

41. Shukla, R.; Pradyumna, S. Energy harvesting in variable stiffness composite piezolaminated plates. Compos. Struct. 2021, 267, 113792. [CrossRef]

42. Gohari, S.; Sharifi, S.; Vrcelj, Z. A novel explicit solution for twisting control of smart laminated cantilever composite plates/beams using inclined piezoelectric actuators. Compos. Struct. 2017, 161, 477-504. [CrossRef]

43. Gohari, S.; Mozafari, F.; Moslemi, N.; Mouloodi, S.; Sharif, S.; Rahmanpanah, H.; Burvill, C. Analytical solution of the electromechanical flexural coupling between piezoelectric actuators and flexible-spring boundary structure in smart composite plates. Arch. Civ. Mech. Eng. 2021, 21, 33. [CrossRef]

44. Pirrera, A.; Avitabile, D.; Weaver, P.M. Bistable plates for morphing structures: A refined analytical approach with high-order polynomials. Int. J. Solids Struct. 2010, 47, 3412-3425. [CrossRef] 